Atmos. Chem. Phys., 13, 10061-10077, 2013

www.atmos-chem-phys.net/13/10061/2013/

doi:10.5194/acp-13-10061-2013

(c) Author(s) 2013. CC Attribution 3.0 License.

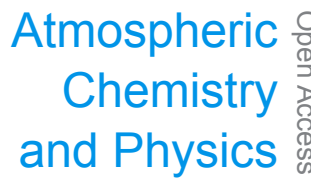

\title{
The fine-scale structure of the trade wind cumuli over Barbados - an introduction to the CARRIBA project
}

\author{
H. Siebert ${ }^{1,2}$, M. Beals ${ }^{8}$, J. Bethke ${ }^{1}$, E. Bierwirth ${ }^{3}$, T. Conrath ${ }^{1}$, K. Dieckmann ${ }^{1}$, F. Ditas ${ }^{1}$, A. Ehrlich ${ }^{3}$, D. Farrell ${ }^{4}$, \\ S. Hartmann ${ }^{1}$, M. A. Izaguirre ${ }^{5}$, J. Katzwinkel ${ }^{1}$, L. Nuijens ${ }^{2}$, G. Roberts ${ }^{6,7}$, M. Schäfer ${ }^{3}$, R. A. Shaw ${ }^{8}$, \\ T. Schmeissner ${ }^{1}$, I. Serikov ${ }^{2}$, B. Stevens ${ }^{2}$, F. Stratmann ${ }^{1}$, B. Wehner ${ }^{1}$, M. Wendisch ${ }^{3}$, F. Werner ${ }^{3}$, and H. Wex ${ }^{1}$ \\ ${ }^{1}$ Leibniz Institute for Tropospheric Research, Leipzig, Germany \\ ${ }^{2}$ Max Planck Institute for Meteorology, Hamburg, Germany \\ ${ }^{3}$ Leipzig Institute for Meteorology, University of Leipzig, Germany \\ ${ }^{4}$ Caribbean Institute for Meteorology and Hydrology, Barbados, West Indies \\ ${ }^{5}$ University of Miami Rosenstiel School of Marine and Atmospheric Science, \\ Met. and Phys. Oceanography, Miami, Florida, USA \\ ${ }^{6}$ Meteo-France, Toulouse, France \\ ${ }^{7}$ Scripps Institution of Oceanography, Center for Atmospheric Sciences, La Jolla, California, USA \\ ${ }^{8}$ Atmospheric Sciences Program, Michigan Technological University, Houghton, MI, USA
}

Correspondence to: H. Siebert (siebert@tropos.de)

Received: 28 September 2012 - Published in Atmos. Chem. Phys. Discuss.: 31 October 2012

Revised: 1 August 2013 - Accepted: 22 August 2013 - Published: 11 October 2013

\begin{abstract}
The CARRIBA (Cloud, Aerosol, Radiation and tuRbulence in the trade wInd regime over BArbados) project, focused on high resolution and collocated measurements of thermodynamic, turbulent, microphysical, and radiative properties of trade wind cumuli over Barbados, is introduced. The project is based on two one-month field campaigns in November 2010 (climatic wet season) and April 2011 (climatic dry season). Observations are based on helicopterborne and ground-based measurements in an area of $100 \mathrm{~km}^{2}$ off the coast of Barbados. CARRIBA is accompanied by long-term observations at the Barbados Cloud Observatory located at the East coast of Barbados since early in 2010 and which provides a longer-term context for the CARRIBA measurements. The deployed instrumentation and sampling strategy are presented together with a classification of the meteorological conditions. The two campaigns were influenced by different air masses advected from the Caribbean area, the Atlantic Ocean, and the African continent which led to distinct aerosol conditions. Pristine conditions with low aerosol particle number concentrations of $\sim 100 \mathrm{~cm}^{3}$ were alternating with periods influenced by Saharan dust or aerosol from biomass burning resulting in comparably high number concentrations of $\sim 500 \mathrm{~cm}^{3}$. The biomass burning aerosol
\end{abstract}

was originating from both the Caribbean area and Africa. The shallow cumulus clouds responded to the different aerosol conditions with a wide range of mean droplet sizes and number concentrations. Two days with different aerosol and cloud microphysical properties but almost identical meteorological conditions have been analyzed in detail. The differences in the droplet number concentration and droplet sizes appear not to show any significant change for turbulent cloud mixing, but the relative roles of droplet inertia and sedimentation in initiating coalescence, as well as the cloud reflectivity, do change substantially.

\section{Introduction and motivation}

Shallow cumulus clouds are a common feature of the trade wind regions (hereafter called the trades). They play an important role in the moisture transport to the free atmosphere (Tiedtke, 1989) and for the earth's radiation budget (Albrecht et al., 1995). Furthermore, shallow cumulus convection significantly influences the dynamics of the sub-cloud layer (SCL) and cloud layer (CL) by intensifying the vertical 
transport of moisture, momentum, and heat from the surface to higher levels (Stevens, 2007).

Since the late 1940s the trades have been in the focus of the scientific cloud community. In a series of pioneering aircraft measurements known as the "Wyman and Woodcock Caribbean Expedition" in April 1946, soundings of wet- and dry-bulb temperature in- and outside the clouds were performed. Based on these observations, new concepts of cloud dynamics and entrainment were tested (Stommel, 1947, 1951). Malkus (1954, 1956, 1958) recognized trade wind cumuli as an example of convective processes under rather uniform and less complex conditions compared to cumuli forming over land in mid-latitudes.

Although the trades have been at the focus of several extensive field experiments since then, such as BOMEX (Barbados Oceanographic and Meteorological EXperiment, Davidson, 1968; Holland and Rasmusson, 1973), ATEX (Atlantic Trade wind EXperiment, Augstein et al., 1973), and more recently RICO (Rain In Cumulus over the Ocean, Rauber et al., 2007), or smaller campaigns such as BACEX (Barbados Aerosol Cloud EXperiment) in 2010, several aspects of trade wind cumuli - in particular small-scale processes such as the role of cloud turbulence - have not been investigated due to measurement limitations, and are still not fully understood.

One of the most important open issues is the rapid formation of precipitation in shallow trade wind cumuli. As the lifetime of trade wind cumuli is relatively short - in the range of hours - formation of precipitation through warm-rain processes is not expected. However, observations indicate the onset of precipitation sometimes in less than one hour. Already Langmuir (1948) pointed out that “... warm cumulus clouds often developed rain within less than thirty minutes after their formation ...".

To clarify this warm-rain problem several topics need further investigation, such as the influence of small-scale turbulence on cloud droplet growth and the importance of atmospheric aerosol particles and cloud condensation nuclei $(\mathrm{CCN})$ on the droplet number concentration, the droplet size, and the amount of drizzle forming from a cumulus cloud (e.g., Heymsfield and McFarquhar, 2001; Kaufman et al., 2005). Giant nuclei are thought to play a particularly important role among the aerosol particles, as they might promote the rapid development of precipitation, a topic mentioned and examined already by Woodcock et al. (1953) and which is still a topic of active research (e.g., Rudich et al., 2002; Blyth et al., 2003). In general, the role of the aerosol particles in controlling radiative properties of clouds may be important e.g., (Twomey, 1977), but the role of the aerosol in driving precipitation, particularly from shallow clouds, remains controversial (Stevens and Feingold, 2009). Quantitatively understanding cloud controlling processes, particularly as it relates to aerosol interactions with shallow cumulus, remains insufficient to advance the representation of these processes in numerical weather prediction and climate models.
Table 1. Schedule of all research flights during CARRIBAWET in 2010 and CARRIBA DRY in 2011.

\begin{tabular}{|c|c|c|c|c|c|c|}
\hline & Flight No & Date & DOY & $\begin{array}{l}\text { Start } \\
\text { UTC }\end{array}$ & $\begin{array}{c}\text { Landing } \\
\text { UTC }\end{array}$ & $\begin{array}{c}\text { Duration } \\
\text { min }\end{array}$ \\
\hline & \#01 & 2010-11-12 & 316 & $14: 17$ & $15: 38$ & $01: 21$ \\
\hline $\mathrm{C}$ & \#02 & 2010-11-12 & 316 & $18: 51$ & $20: 27$ & $01: 35$ \\
\hline A & \#03 & $2010-11-13$ & 317 & $13: 14$ & $14: 37$ & 01:22 \\
\hline $\mathrm{R}$ & \#04 & $2010-11-13$ & 317 & $17: 45$ & $19: 23$ & $01: 38$ \\
\hline $\mathrm{R}$ & \#05 & 2010-11-14 & 318 & $17: 26$ & $18: 55$ & $01: 28$ \\
\hline I & \#06 & $2010-11-15$ & 319 & $14: 07$ & $15: 40$ & 01:32 \\
\hline B & \#07 & $2010-11-16$ & 320 & $14: 43$ & $15: 54$ & 01:10 \\
\hline \multirow[t]{2}{*}{ A } & \#08 & $2010-11-20$ & 324 & $16: 52$ & $18: 40$ & $01: 48$ \\
\hline & \#09 & $2010-11-21$ & 325 & $13: 30$ & $15: 21$ & $01: 50$ \\
\hline $\mathrm{W}$ & $\# 10$ & 2010-11-21 & 325 & $18: 45$ & $20: 46$ & 02:01 \\
\hline $\mathrm{E}$ & \#11 & $2010-11-22$ & 326 & $13: 53$ & $15: 44$ & 01:50 \\
\hline \multirow[t]{6}{*}{$\mathrm{T}$} & \#12 & $2010-11-23$ & 327 & $13: 32$ & $15: 34$ & 02:01 \\
\hline & \#13 & $2010-11-24$ & 328 & $13: 29$ & $15: 25$ & $01: 56$ \\
\hline & \#14 & $2010-11-25$ & 329 & $13: 31$ & $15: 24$ & 01:52 \\
\hline & $\# 15$ & $2010-11-26$ & 330 & $14: 00$ & $15: 47$ & 01:47 \\
\hline & \#16 & $2010-11-27$ & 331 & $13: 31$ & $15: 26$ & $01: 54$ \\
\hline & $\# 17$ & 2011-04-09 & 99 & $13: 30$ & $15: 08$ & $01: 36$ \\
\hline $\mathrm{C}$ & \#18 & 2011-04-10 & 100 & $13: 44$ & $15: 29$ & 01:44 \\
\hline A & \#19 & 2011-04-13 & 103 & $13: 47$ & $15: 28$ & 01:40 \\
\hline $\mathrm{R}$ & \#20 & 2011-04-14 & 104 & $13: 53$ & $15: 46$ & 01:53 \\
\hline $\mathrm{R}$ & \#21 & 2011-04-14 & 104 & $19: 35$ & $21: 35$ & 01:59 \\
\hline I & \#22 & 2011-04-15 & 105 & $13: 41$ & $15: 24$ & $01: 43$ \\
\hline B & \#23 & 2011-04-16 & 106 & $13: 39$ & $15: 23$ & 01:44 \\
\hline \multirow[t]{2}{*}{ A } & \#24 & 2011-04-18 & 108 & $13: 44$ & $15: 29$ & 01:44 \\
\hline & \#25 & 2011-04-19 & 109 & 13:04 & $14: 47$ & 01:42 \\
\hline $\mathrm{D}$ & \#26 & 2011-04-19 & 109 & $18: 30$ & $20: 23$ & $01: 52$ \\
\hline $\mathrm{R}$ & \#27 & 2011-04-20 & 110 & $14: 27$ & $16: 21$ & $01: 53$ \\
\hline \multirow[t]{4}{*}{$\mathrm{Y}$} & \#28 & 2011-04-22 & 112 & $13: 29$ & $15: 22$ & 01:53 \\
\hline & \#29 & $2011-04-23$ & 113 & $13: 27$ & $15: 24$ & $01: 56$ \\
\hline & \#30 & 2011-04-24 & 114 & $14: 13$ & $16: 07$ & $01: 54$ \\
\hline & \#31 & $2011-04-25$ & 115 & $13: 50$ & $15: 42$ & $01: 51$ \\
\hline
\end{tabular}

Following Malkus' point of view, the trades provide unique laboratory-like conditions for investigating crucial cloud processes in nearly stationary conditions. Furthermore, besides ship and aircraft emissions there are no significant anthropogenic aerosol sources upwind of Barbados for several thousands of kilometers. Therefore, the upwind coast of Barbados seems almost ideal to investigate the influence of aerosol layers advected by large-scale transport. In certain seasons, mineral dust advected from the Sahara is the dominant aerosol over Barbados (Prospero and Carlson, 1972; Smirnov et al., 2000; Reid et al., 2002). In addition, aerosol particles originating from biomass burning in Africa can frequently be observed from 1 to $4 \mathrm{~km}$ height (e.g., Haywood et al., 2008). The long-range transport of this aerosol type from the Sahara over the Atlantic and its influence on the Barbados region is discussed by Kaufman et al. (2005). Examining the influence of these aerosol particles reaching Barbados by large-scale advection or by production on the island itself, may shed light on the different aspects of shallow cumulus dynamics and the importance of aerosol particles therein. 
Therefore, the CARRIBA-project (Cloud, Aerosol, Radiation and tuRbulence in the trade wInd regime over BArbados) was initiated by the Leibniz Institute for Tropospheric Research (TROPOS). The project is based on two one-month experiments with the ACTOS (Airborne Cloud Turbulence Observation System) and SMART-HELIOS (Spectral Modular Airborne Radiation measurement sysTem) payloads along with ground-based aerosol characterization. The first campaign was performed in November 2010, at the end of the climatic wet season and is called CARRIBA ${ }_{\mathrm{WET}}$, the second

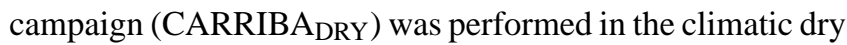
season in April 2011. CARRIBA is embedded within a longterm initiative of the Max Planck Institute for Meteorology (MPI-M), which operates the Barbados Cloud Observatory (BCO) located at the East coast of Barbados since early in 2010, thereby providing a longer-term context for the CARRIBA measurements (e.g., Nuijens et al., 2013).

Beside the MPI-M, the local Caribbean Institute for Meteorology and Hydrology (CIMH) on Barbados is a partner in this project. In addition, long-term dust measurements which have continuously been performed since 1964 by the University of Miami are available from an upwind site at "Ragged Point", a location at the eastern most tip of Barbados, where several systems for a thorough ground-based aerosol characterization were additionally deployed for CARRIBA (see Sect. 2.3).

With instrumentation such as the high resolution helicopter-borne ACTOS together with recently developed aerosol characterization methods, and collocated radiation observations with SMART-HELIOS in combination with ground-based spectral imaging sensors (see Sect. 2 for instrumentation), powerful tools were applied during CARRIBA to make steps forward in understanding fundamental cloud and aerosol processes. This suite of instrumentation provides a very high resolution, localized view of aerosol-cloudturbulence-radiation processes, complementing the broader view gained in some of the recent, larger field projects in the trades. Therefore, in contrast to the already mentioned prior field projects, CARRIBA is more focused on local scales including the small-scale structure of individual clouds.

The main research interests of CARRIBA and the interplay of the related physical processes in and around a shallow cumulus cloud are illustrated in Fig. 1 together with a brief view of the sampling strategy with the two helicopterborne measurement payloads. The objectives of CARRIBA in terms of four leading topics are briefly introduced below:

- Clouds: the cloud microphysical properties in terms of droplet number concentration and size distribution of trade wind clouds are investigated for different cloud regions and conditions. Beside fundamental questions like how large droplets form in a turbulent shallow cumulus, the focus is on the question of how the clouds respond to different aerosol conditions observed during the two campaigns.

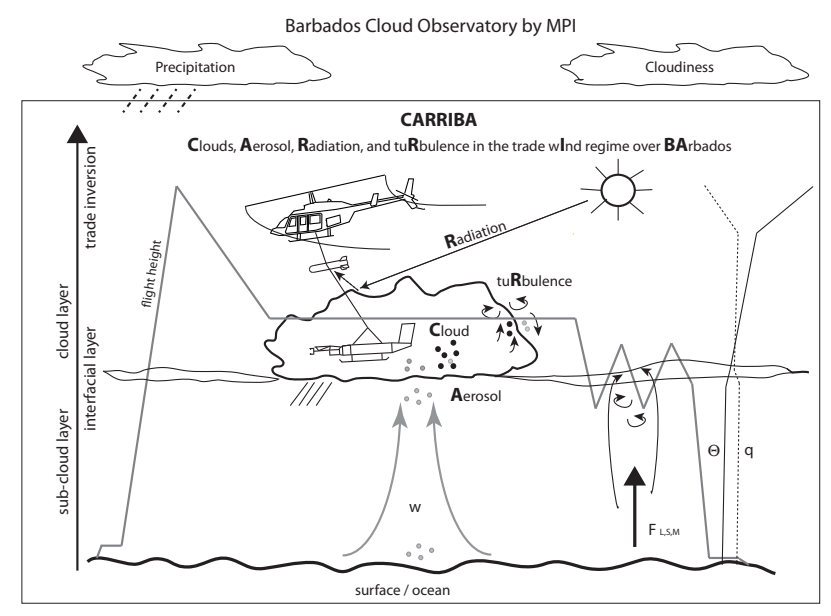

Fig. 1. The cartoon illustrates the cloud processes of the four main topics of the CARRIBA project: Clouds, Aerosol, Radiation, and tuRbulence in trade wInd regime over BArbados and how the helicopter-borne measurements are embedded in the long-term remote-sensing observations in terms of cloudiness and precipitation performed at the Barbados Cloud Observatory (BCO).

- Aerosol: the physical aerosol properties in the subcloud and cloud layer and the aerosol stratification are investigated for different meteorological conditions. One major topic is how the aerosol particles influence the cloud properties as well as how clouds influence the aerosol conditions in the cloud layer.

- Solar radiation: the susceptibility of trade wind cumuli to different aerosol environments is studied by applying remote sensing techniques (combined with in situ measurements) for spectral reflected solar radiation. The remote sensing results of optical and microphysical properties of trade wind cumuli are compared with collocated in situ data.

- Turbulence: the turbulent dynamics and thermodynamics of the sub-cloud layer, cloud environment, and cloud edges including the entrainment process are investigated. Furthermore, the turbulent in-cloud mixing and its influence on the cloud microphysical properties are quantified by determining the governing timescales and dimensionless numbers.

This article is intended as a general introduction and overview of the CARRIBA-project, as well as an illustration of unique aspects of the data set collected, for those interested in using the data, or considering similar measurement campaigns. After a classification of the weather situation observed during the two CARRIBA campaigns with emphasis on the cloud situation and the thermodynamic structure of the lower troposphere, a case study based on two days with nearly identical stratification, dynamic, and thermodynamic conditions is presented. The only substantive difference is in 
the aerosol load observed in the SCL and the resulting cloud microphysical properties. The consequences of the different cloud properties for cloud-turbulence interaction and radiation effects are discussed. This example nicely illustrates the unique possibilities of our deployed measurement setup and helps motivate the project as a whole, and the sampling strategies that were employed.

\section{Instrumentation and sampling strategy}

\subsection{Location of measurement sites and sampling strategy}

The helicopter was operated from a helipad located at the Concorde Experience Museum at Grantley Adams International Airport (GAIA, see map in Fig. 2). The main operational area was an area of roughly $100 \mathrm{~km}^{2}$ upwind of the BCO and Ragged Point sites which were supplemented with additional aerosol, meteorological and radiation measurements as part of CARRIBA (see map in Fig. 2). Typically, research flights began with a vertical profile up to a height of 2 to $3 \mathrm{~km}$ followed by several horizontal flight legs flown between two pre-defined navigation points (C1 and C2, see map in Fig. 2) separated by about $10 \mathrm{~km}$ and oriented in south-north direction. With this sampling strategy, the influence of the island was kept minimal and a direct comparison between helicopter-borne profiling, remotesensing and radio-soundings at the BCO and aerosol measurements at Ragged Point is facilitated. During the second half of the flights, cloud sampling was performed in a semirandom fashion according to the present development and accessibility of shallow cumulus. To illustrate a typical flight pattern, one flight path of a two-hour flight (\#18 from 10 April 2011, see Table 2 for an overview of all flight numbers and dates) is shown as a red line together with its corresponding height profile in the upper right part of Fig. 2. Blue lines indicate cloud penetrations. A second measurement area was defined in the south of the island as an alternative in case of possible conflict with commercial air traffic.

All flight paths from both campaigns have been included in Fig. 2 as thin lines (orange for CARRIBA WET $_{\text {and }}$ grey for CARRIBA $\left._{D R Y}\right)$. The three main operational areas are marked in Fig. 2 as colored boxes. About $80 \%$ of cloud sampling was performed within the gray box a, almost all profiling was performed within the green box $\mathrm{c}$ and four flights had to be performed in the orange box b due to conflicts with air-

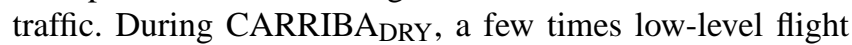
legs were flown about $50 \mathrm{~m}$ above sea level in order to investigate air-sea interaction. This was done shortly after take-off while approaching point $\mathrm{C} 1$.

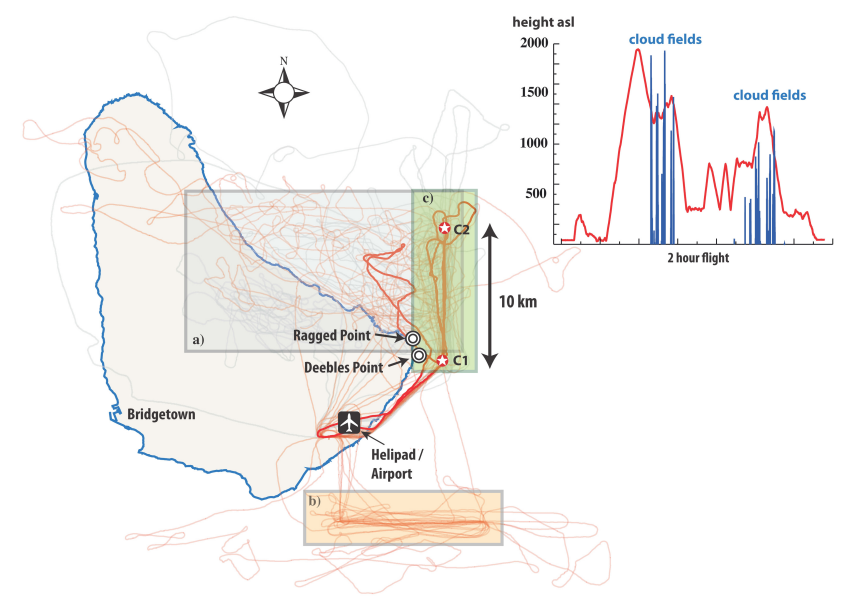

Fig. 2. A map of Barbados including the location of the helipad for the ACTOS operation and the two stations at Deebles Point and Ragged Point. For both campaigns the tracks of all ACTOS flights are shown, the orange lines are for CARRIBAWET and the gray

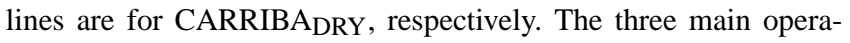
tional areas are marked by colored boxes: (a) area were about $80 \%$ of the cloud sampling took place, (b) alternative area only used during the first flights of CARRIBAWET for conditions with higher commercial traffic load, and (c) box with the two navigation points $\mathrm{C} 1$ and C2 for profiling. The flight of 10 April 2011 is marked as red line. For this example the measurement height is presented in the upper right panel together with sampled clouds (blue lines) to illustrate the flight strategy.

\subsection{ACTOS and SMART-HELIOS}

\subsubsection{The ACTOS payload}

During the two CARRIBA field campaigns, helicopter-borne measurements were performed with ACTOS (Siebert et al., 2006a) which is an autonomous measurement payload carried by means of a $140 \mathrm{~m}$ long kevlar cable as external cargo. The long rope and a typical true airspeed of $20 \mathrm{~m} \mathrm{~s}^{-1}$ of the helicopter avoid any measurable influence of the rotor downwash. The overall length of ACTOS (Fig. 3) is about $5 \mathrm{~m}$ and the total weight is limited to $200 \mathrm{~kg}$. The main body consists of five 19" standard racks in which most of the sensor electronics, power supplies, and data acquisition systems are located. The sensors themselves are located on a carbon fibre outrigger on the front of ACTOS so as to avoid possible aerodynamic influences. A passive tail unit keeps ACTOS aligned in the mean flow direction.

ACTOS can be operated up to a height of about $3000 \mathrm{~m}$ and is restricted to shallow cumulus conditions, that is, deep convective clouds have to be avoided for safety reasons. Due to general flight rules, the helicopter remains above the clouds and ACTOS is dipped into the clouds from above. Due to the typical low gustiness observed in the trades, the wind speed was not a serious restriction for flight operation during the campaigns. 
Table 2. Summary of mean SCL and in-cloud parameters for April 22 and April 24.

\begin{tabular}{|c|c|c|c|c|c|c|c|c|c|c|c|c|}
\hline \multirow[t]{2}{*}{ Day } & \multicolumn{6}{|c|}{ Mean SCL values } & \multicolumn{6}{|c|}{ Mean in-cloud values } \\
\hline & $\begin{array}{l}\Theta \\
K\end{array}$ & $\begin{array}{c}q \\
\mathrm{~g} \mathrm{~kg}^{-1}\end{array}$ & $\begin{array}{c}U \\
\mathrm{~ms}^{-1}\end{array}$ & $\begin{array}{c}d \\
\circ\end{array}$ & $\mathrm{cm}^{-3}$ & $\begin{array}{l}N_{\mathrm{CCN}} \\
\mathrm{cm}^{-3}\end{array}$ & $\begin{array}{c}T \\
{ }^{\circ} \mathrm{C}\end{array}$ & $\begin{array}{c}p \\
\mathrm{hPa}\end{array}$ & $\begin{array}{c}N_{d} \\
\mathrm{~cm}^{-3}\end{array}$ & $\begin{array}{c}d_{\mathrm{MVD}} \\
\mu \mathrm{m}\end{array}$ & $\begin{array}{l}r_{\text {eff }} \\
\mu \mathrm{m}\end{array}$ & $\mathrm{m}^{2} \mathrm{~s}^{-3}$ \\
\hline $22 \mathrm{Apr}$ & 301 & 16.3 & $8-10$ & 90 & 115 & 40 & 15 & 840 & 42 & 38 & 18 & $2 \times 10^{-3}$ \\
\hline $24 \mathrm{Apr}$ & 301 & 16.3 & $6-8$ & 110 & 265 & 160 & 14 & 828 & 80 & 27 & 12 & $3 \times 10^{-3}$ \\
\hline
\end{tabular}

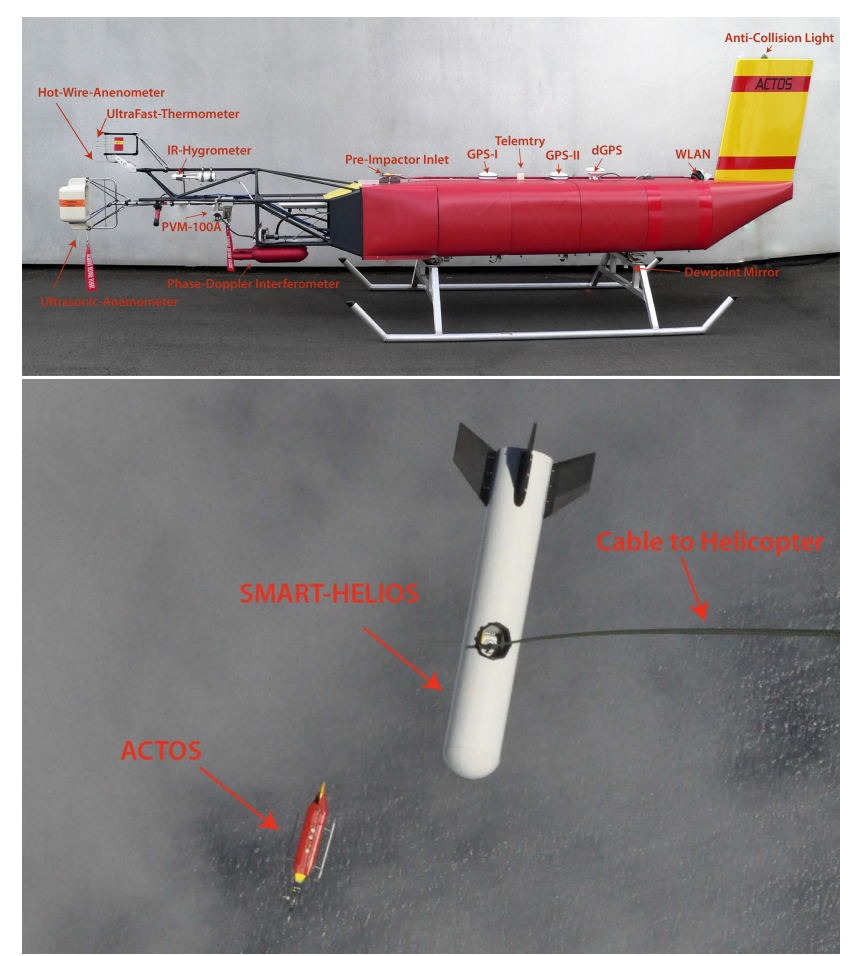

Fig. 3. Upper panel: ACTOS with its main sensors located at the carbon fibre outrigger. The data acquisition, sensors electronics, and power supply are located in the $19^{\prime \prime}$ racks behind the red covers. Lower panel: ACTOS with SMART-HELIOS entering a field of fluffy cumulus clouds over the Caribbean Ocean.

The standard ACTOS instrumentation comprises sensors for the wind vector, temperature, and humidity under clear and cloudy conditions. The measured wind vector is transformed into an earth-fixed system using information about the payload position, attitude, and velocity taken from the GPS and inertial navigation systems (see Wendisch and Brenguier, 2013 for details). In addition to a PVM-100A (Gerber et al., 1994), which measures the integral properties of the cloud droplet spectrum, a Phase Doppler Interferometer (PDI) for single droplet measurements in the size range of 1 to $180 \mu \mathrm{m}$ is included (Chuang et al., 2008; Wendisch and Brenguier, 2013).

ACTOS is additionally equipped with a variety of sensors to measure aerosol microphysical properties. The aerosol in- struments are supplied by one common aerosol inlet (except the Fast-CPC) which is designed for sampling particles up to diameters of $3 \mu \mathrm{m}$. This ensures that cloud droplets cannot enter the system. The inlet is followed by a dryer to keep the relative humidity below $40 \%$. Aerosol particle number concentration $\left(N_{\mathrm{p}}\right)$ is detected by two CPCs (Condensation Particle Counters). The commercial TSI-CPC (model 3762, TSI Inc., St. Paul, USA; operated with a temperature difference between saturator and condenser of $25 \mathrm{~K}$ ) measures $N_{\mathrm{p}}$ for particles larger than $7 \mathrm{~nm}$ with a measurement frequency of approximately $1 \mathrm{~Hz}$. The second CPC measures particles larger than $7 \mathrm{~nm}$ with a frequency of $50 \mathrm{~Hz}$ (hereafter referred to as Fast-CPC, see Wehner et al., 2011). The aerosol number size distribution was measured by a Scanning Mobility Particle Sizer (SMPS, see Wehner et al., 2010) providing a full spectrum between 77 and $230 \mathrm{~nm}$ at a time resolution of $2 \mathrm{~min}$. For larger aerosol particles an Optical Particle Counter (OPC, model 1.129 "SKY-OPC", Grimm Aerosol Technik GmbH, Ainring, Germany) gives information about the aerosol number size distribution in the range of 300 to $2676 \mathrm{~nm}$ at a measurement frequency of $1 \mathrm{~Hz}$. Additionally, a mini-CCNC (Cloud Condensation Number Counter) was used for measuring the $\mathrm{CCN}$ number concentration at different supersaturations (Roberts and Nenes, 2005). A similar instrument was also used for the ground-based aerosol characterization at the Ragged Point site during CARRIBA (see below). With the given true airspeed of ACTOS the spatial resolution for the Fast-CPC measurements are on the decimeter scale.

\subsubsection{The SMART-HELIOS payload}

The reflection of solar radiation by clouds was measured by SMART-HELIOS (see lower picture in Fig. 3). Two optical inlets for upward spectral radiance $I_{\lambda}^{\uparrow}$ and upward spectral irradiance $F_{\lambda}^{\uparrow}$ are connected with two plane grating spectrometers, for the visible (VIS, 300 to $1000 \mathrm{~nm}$ ) and near-infrared (NIR, 900 to $2100 \mathrm{~nm}$ ) spectral range. In the VIS the spectrometer has a full width at half maximum of 2 to $3 \mathrm{~nm}$, in the NIR of 8 to $10 \mathrm{~nm}$. $I_{\lambda}^{\uparrow}$ and $F_{\lambda}^{\uparrow}$ were sampled with a temporal resolution of 0.1 to $1 \mathrm{~s}$. This temporal resolution and the opening angle of the radiance inlet of about $2^{\circ}$ yield a spatial resolution of about $5 \mathrm{~m}$, when SMART-HELIOS is measuring $140 \mathrm{~m}$ above the trade wind cumuli. Measurement uncertainties result from spectral and calibration uncertainties and 
are in the range of $6 \%$ in the VIS and $10 \%$ in the NIR. Observations of closely collocated in situ and cloud reflectivity data by ACTOS and SMART-HELIOS have been described by Henrich et al. (2010) and Werner et al. (2013a, b).

SMART-HELIOS does not measure downward radiation due to its location below the helicopter. As a consequence, the downward radiation has to be calculated. To help verify these simulations, additional ground-based radiance measurements with the hyper-spectral imaging spectrometer AisaEAGLE were performed (Schäfer et al., 2013). The measurements were conducted at the BCO and were performed in parallel with all helicopter flights.

The AisaEAGLE is a single line sensor with 1024 spatial pixels that cover a field of view of $36.7^{\circ}$ (Hanuš et al., 2008). By aligning the sensor perpendicular to the movement of the clouds, two-dimensional measurements of transmitted radiances with high spatial resolution were obtained. For a cloud altitude of $2000 \mathrm{~m}$ the size of a single image pixel is about $1.3 \mathrm{~m}$ with $1300 \mathrm{~m}$ swath. The high resolution allows detailed studies of cloud inhomogeneities and cloud edges. Schmidt et al. (2009) and Chiu et al. (2009) demonstrated that spectral radiation in the vicinity of clouds can be used to discriminate cloud and aerosol radiative effects.

For each spatial pixel AisaEAGLE measures the transmitted spectral radiance between $400 \mathrm{~nm}$ and $970 \mathrm{~nm}$ at 488 wavelength pixels. The spectral resolution is $1.25 \mathrm{~nm}$ full width at half maximum which is comparable to SMARTHELIOS and which allows analysis of the blueing effect of aerosol optical thickness in the presence of threedimensional cloud effects as proposed by Marshak et al. (2008).

\subsection{Aerosol instrumentation at Ragged Point}

During both CARRIBA campaigns, accompanying groundbased measurements were performed to obtain a continuous characterization of basic aerosol parameters for the duration of the campaigns. For this, we were able to use the facility operated by the University of Miami at Ragged Point (see Fig. 2) where mineral dust measurements have been made continuously for more than forty years (Prospero and Lamb, 2003). An aerosol inlet on top of a $17 \mathrm{~m}$ high mast directly at the top of the cliffs at Ragged Point was used to sample the aerosol. Measurements were made in a ground based, air conditioned container connected by an inlet line. The aerosol was dried to a relative humidity below $25 \%$ using diffusion dryers. The aerosol instrumentation operated at Ragged Point during CARRIBA included a DMPS (Differential Mobility Particle Sizer), with a DMA (Differential Mobility Analyzer, Type Vienna medium) and a CPC (model 3010, TSI Inc., St. Paul, USA) operating from 25 to $500 \mathrm{~nm}$. Furthermore, a CCNC (Roberts and Nenes, 2005) measuring activation to cloud droplets for size segregated aerosol (i.e., operating in parallel to the DMPS-system); and a mini-CCNC (Roberts and Nenes, 2006), which measured total CCN concentra- tions, while the supersaturation was scanned from $0.1 \%$ to $1 \%$, and which is the counterpart to a sister instrument flown on ACTOS. The measured size distributions can be integrated to yield the total particle number concentrations $N_{\mathrm{p}}$ for the respective size range. Additionally to this instrumentation, daily filter samples were taken on top of the mast and analyzed with regard to the chemical bulk composition of the aerosol particles.

\section{Classification of the two observational periods}

In this section, an overview of the meteorological, cloud, and aerosol conditions during the two campaigns is provided. Cloudiness - in terms of cloud cover and the distribution of cloud base heights - and the humidity stratification during the two campaign periods will be compared with a twoyear climatology. The latter is derived from two-year of RAMAN lidar and ceilometer measurements at the BCO, operational analysis from the European Center for Medium Range Weather Forecasts (ECMWF) and averaged ACTOS flight data. In Sect. 3.1 the different data sets are introduced which are then jointly discussed in Sect. 3.2.

\subsection{The data}

Figure 4 shows the volume depolarization ratio from the Raman lidar and the low-level (below $5 \mathrm{~km}$ ) cloud cover derived from ceilometer data averaged over $6 \mathrm{~h}$, both measured at $\mathrm{BCO}$. The volume depolarization ratio can be considered as a dust indicator, but shows little sensitivity to aged aerosol particles produced by biomass burning. The upper panels show the time period from April 2010 to January 2012. The two CARRIBA campaigns are marked with colored boxes and enlarged in the lower panels. Rain showers are visible in the lidar data as short white gaps representing missing data, because the lidar system shuts down when rain is present. The long data gap at the beginning of CARRIBAWET is due to a power outage related to the hurricane Tomas that passed over Barbados.

Figure 5 shows profiles of specific humidity $q$, potential temperature $\theta$ and relative humidity RH derived from 12:00 UTC ECMWF operational analysis at a single gridpoint near Barbados $\left(59.02^{\circ} \mathrm{W}, 13.14^{\circ} \mathrm{N}\right)$, as well as the frequency of detecting cloud bases at any height derived from the ceilometer operating at the BCO. The dashed black lines in all panels indicate a two-year mean, from April 2010 to January 2012. Also shown are the mean profiles during days when ACTOS was flying, in solid black (OP ECMWF) and solid blue (ceilometer). The profiles measured by ACTOS during flight hours are shown in thick solid orange and red, similarly the cloud base heights measured during those flight hours by the ceilometer are shown in thick blue lines. We also show the mean RAMAN lidar humidity profiles between 07:00-09:00 UTC on ACTOS flight days. The RAMAN lidar 

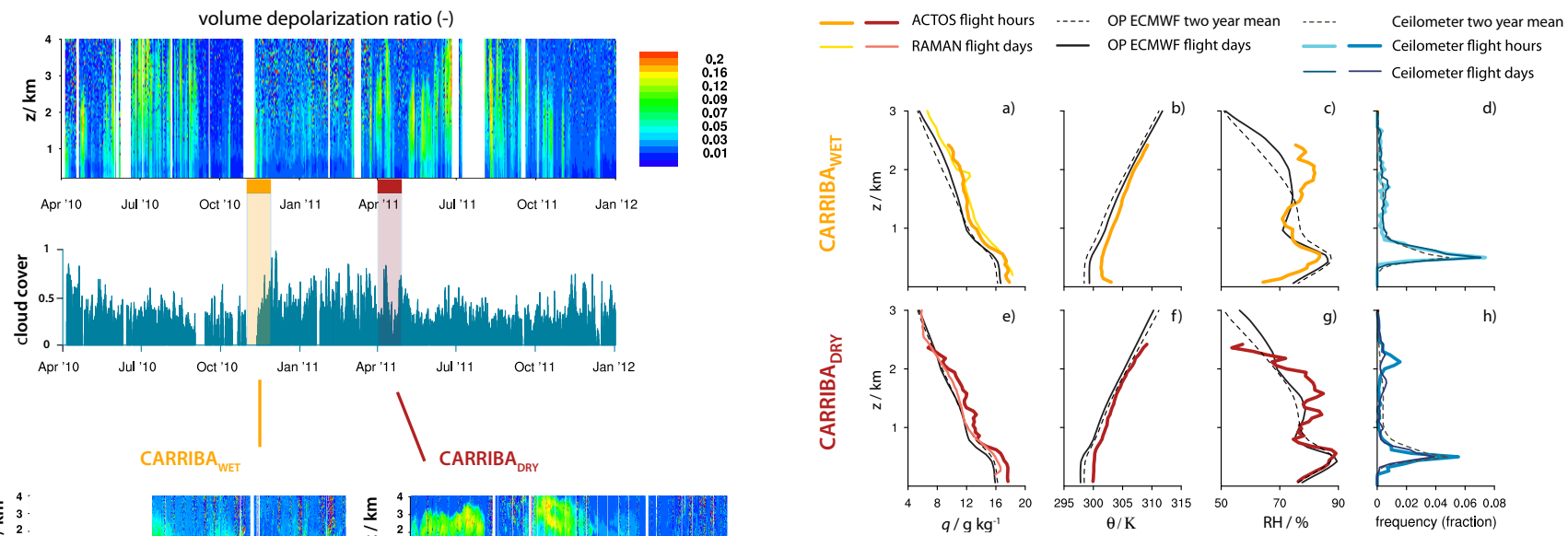
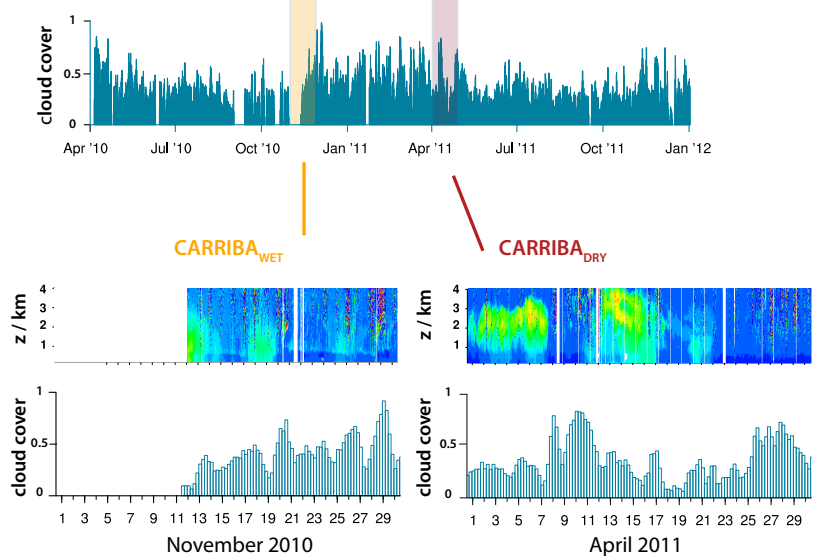

Fig. 4. Time series of volume depolarization ratio measured by the Raman lidar and ceilometer-derived low level cloud cover (fraction of time with a cloud base height $<5 \mathrm{~km}$ ) both measured at BCO. Below are zoom ins on the two CARRIBA periods in November 2010 and April 2011. The long data gap at the beginning of CARRIBAWET was due to a power outage related to the hurricane Tomas that passed over Barbados.

only measures humidity profiles during nighttime (22:0009:00 UTC), hence we choose the early morning 07:0009:00 UTC timeframe to match the ACTOS flights closest in time. When comparing ACTOS with the OP ECMWF, one should keep in mind that the ACTOS flights were performed under favorable cloud conditions, implying that times with deep convective clouds and heavy rain showers were avoided, instead situations with typical trade wind clouds were preferred. This selection of flight times might bias the comparison.

Mean values of selected quantities for each individual research flight have also been calculated after classifying the data into three categories: (i) data sampled in the SCL below $400 \mathrm{~m}$. For this class only data sampled over the ocean are considered to minimize land effects. (ii) Data in the height range between $700 \mathrm{~m}$ and $2 \mathrm{~km}$ but out off clouds, and (iii) all cloud data in the same height range. Here, cloud data is defined by a liquid water content (LWC) $>0.05 \mathrm{~g} \mathrm{~m}^{-3}$. In this paper, we present the effective radius $r_{\text {eff }}$ (see Fig. 6e) instead of the size distribution itself. The effective radius is calculated as the ratio between the third and second moment of the size distribution. The results are presented in Fig. 6 for both campaigns.
Fig. 5. Profiles of specific humidity $q$ (a, e), potential temperature $\theta(\mathbf{b}, \mathbf{f})$, relative humidity $\mathrm{RH}(\mathbf{c}, \mathbf{g})$, and the vertical distribution of cloud base heights $(\mathbf{d}, \mathbf{h})$. Black dashed lines show the two year mean humidity and temperature profiles, derived from ECMWF operational analysis (12:00 UTC) for a single grid point near Barbados, and two year of ceilometer-derived cloud base heights. The mean profiles during ACTOS flight days only are shown as black solid lines (EMCWF OP) and dark blue solid lines (ceilometer). The RAMAN lidar humidity profiles during 07:00-09:00 UTC on ACTOS flight days are shown as yellow and rose. Profiles measured by ACTOS are shown as thick orange and red lines, and the corresponding cloud base heights as thick light and dark blue lines. Top panels are for CARRIBAWET, bottom panels are the same, but for CARRIBA ${ }_{D R Y}$.

\subsection{Discussion}

The typical amount of precipitation in November is $170 \mathrm{~mm}$ (climatic wet season) compared with $60 \mathrm{~mm}$ in April (climatic dry season), based on a $30 \mathrm{yr}$ record measured at the airport (period from 1981 to 2010). However, after a significant amount of precipitation at the end of October 2010 due to hurricane Tomas - on 30 October 2010 about $235 \mathrm{~mm}$ was measured, the highest daily value observed within the last 30 $\mathrm{yr}$ - November 2010 was comparably dry with only $65 \mathrm{~mm}$. CARRIBA $_{D R Y}$ in April 2011, on the other hand, experienced a total amount of precipitation of $143 \mathrm{~mm}$, mainly due to a few days with heavy shower activity at the end of the month. Compared to the climatology, the CARRIBAwET campaign was therefore much drier than the CARRIBA ${ }_{D R Y}$ campaign, but because ACTOS flights took place mostly during nonraining periods, the unusual rainy conditions did not bias the observations. In fact, in terms of the cloud field both campaigns experienced very similar conditions, with cloud cover frequently peaking above 0.5 (Fig. $4 \mathrm{~b}$ ) and the day-to-day variability being high (Fig. 4b, e and f).

During both campaigns the overall meteorology was quite similar, with easterly winds dominating and typical wind speeds being on the order of 5 to $10 \mathrm{~m} \mathrm{~s}^{-1}$ (Fig. 6a, b). During most flights, no significant vertical shear was observed, 


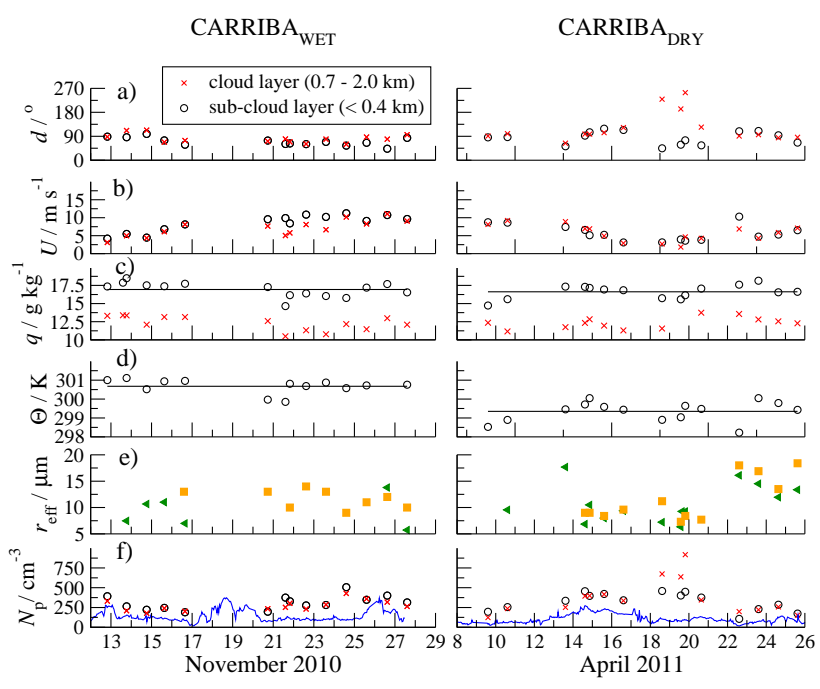

Fig. 6. Overview of the meteorological situation during

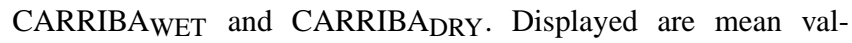
ues representative for the SCL below $400 \mathrm{~m}$ (black circles) and the cloud-free layer in the height range between 0.7 and $2.0 \mathrm{~km}$ (red crosses). Only data from over the ocean is considered for the SCL height. Displayed are the mean wind direction $d$, the mean horizontal wind velocity $U$, the specific humidity $q$, the potential temperature $\Theta$, and the aerosol particle number concentration $N_{\mathrm{p}}$. The solid blue line represents the particle number concentration with diameters $>80 \mathrm{~nm}$ (a proxy for $\mathrm{CCN}$ at $S \approx 0.2 \%$ ) as continuously measured at Ragged Point. The mean effective radius $r_{\text {eff }}$ is estimated for cloud fields in the height range between 0.7 and $2.0 \mathrm{~km}$, the orange symbols are in situ estimates derived from the PDI and the green symbols are retrievals from radiation measurements representative for cloud top.

that is, the wind velocity was similar in the SCL and the CL. Only for a four-day period in November 2010 (20th to 24th) the wind record indicates some vertical shear with stronger winds in the SCL compared to higher levels. A second exceptional period took place in April 2011 when the trades were disturbed for a three-day period between 18 to 21 April and the wind in the SCL turned to north-east, whereas winds in the CL were from the south-west. This period coincided with the weakest wind speed observed during the two campaigns, $U<5 \mathrm{~m} \mathrm{~s}^{-1}$ (cf. Fig. 6b).

The prevailing easterlies in combination with a quite constant sea-surface temperature resulted in quite stable temperature conditions in the SCL (over water) with $\bar{\Theta}=300.6 \mathrm{~K}$ in November 2010 compared with $\bar{\Theta}=299.3 \mathrm{~K}$ in April 2011 (Fig. 6d). The day-to-day variation of the mean temperature in the SCL was typically below $0.5 \mathrm{~K}$. The specific humidity (Fig. 6c) during both campaigns had a mean value around $17 \mathrm{~g} \mathrm{~kg}^{-1}$ and a standard deviation of $\sim 1 \mathrm{~g} \mathrm{~kg}^{-1}$, based on all flights. The two days with the lowest observed humidity values in the SCL (morning flight on 21 November 2010 and 9 April 2011) were the only two flights without any clouds in the measurement area. Both days show also the lowest temperatures in the SCL (Fig. 6d).

The mean $q$ profiles measured with ACTOS, as well as with the RAMAN lidar, are 1 to $2 \mathrm{~g} \mathrm{~kg}^{-1}$ moister compared to the OP ECMWF profiles during both CARRIBAWET and CARRIBA $_{\text {DRY }}$, especially in the SCL during April 2011 (Fig. 5a). The data assimilation performed at ECMWF is based on radiosondes which are regularly launched from the Barbados airport. However, the location from where they are launched, together with the prevailing wind direction might cause a dry bias in the measured profiles. Because the ACTOS profiles are derived from highly accurate fast dew point mirror measurements performed over the open ocean, and the RAMAN lidar is also located directly at the coastline, landocean differences, especially in the SCL, may play a role in explaining these differences. Because the mean ACTOS profiles are based on only one profile per flight and the water vapor field is highly variable in both space and time, one should keep in mind that ACTOS profiles likely do not represent the mean conditions during these months. Based on the ECMWF OP and the RAMAN lidar profiles, we believe that ACTOS flights were performed under somewhat warmer and moister conditions during CARRIBAWET, and drier and colder con-

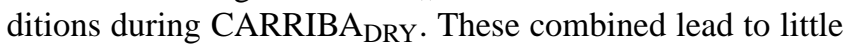
difference in the relative humidity profiles in the SCL, and little differences in the overall frequency of detecting cloud, although cloud fraction near cloud base $(500 \mathrm{~m})$ was somewhat higher during CARRIBAwET.

Both the ECMWF OP and ACTOS profiles show that the $\mathrm{RH}$ in the lower cloud layer, between $700 \mathrm{~m}$ and $1.8 \mathrm{~km}$,

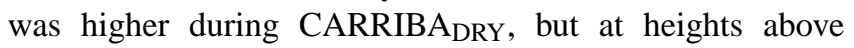
$2 \mathrm{~km}$, both $q$ and $\mathrm{RH}$ decrease more sharply compared to CARRIBAWET. This indicates a stronger inversion during CARRIBA $_{D R Y}$. Indeed, during April months the large-scale subsidence (not shown) is generally stronger than during November months, leading to a more stable and drier atmosphere. The peak in detected cloud base heights just above

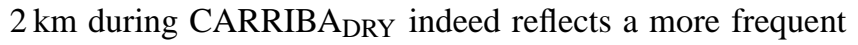
occurrence of extended cloud layers near cloud top that likely result from this stronger inversion.

The aerosol particle number concentration $N_{\mathrm{p}}$ observed during ACTOS flights (Fig. 6f) is in general on the order of a few hundred particles $\mathrm{cm}^{-3}$. Typically, the concentration in the SCL and in higher levels is quite similar and there is only a small decrease of $N_{\mathrm{p}}$ with height. Only the westerly winds on 18 to 21 April 2011 advected a significantly increased aerosol particle number concentration at higher levels.

At the beginning of CARRIBA WET (11 to 13 November) and from 17 to 19 November, Barbados was significantly influenced by advected Saharan dust which is visible in the volume depolarization ratio of the lidar in Fig. 4. The dust layers reached heights of up to 2 to $3 \mathrm{~km}$ but a significant amount of dust was also mixed down and increased particle number concentration was observed at Ragged Point (see concentration in Fig. 6 for particles $>80 \mathrm{~nm}$ ). Unfortunately, 
for the second dust period no flight data is available. For both periods, air masses originated from regions in Africa with biomass burning mixed with Saharan dust influenced the situation in Barbados. However, biomass burning aerosol does not contribute to the volume depolarization ratio but results in a generally increased particle number concentration. During a third period between 25 and 26 November an increased volume depolarization ratio in the lidar signal was observed in a layer roughly between 1 and $2 \mathrm{~km}$ indicating again advected dust. During this period the downward mixed dust resulted in a slightly reduced lidar signal compared to the main layer. In situ data at Ragged Point and from ACTOS do well agree with the lidar observations. The slightly higher concentrations observed by ACTOS result from particles smaller than $80 \mathrm{~nm}$. Again, aerosol which originated from biomass burning was partly influencing the situation over Barbados. During clean periods, for example around 21 November, often increased number concentrations of Aitken-mode particles $(<80 \mathrm{~nm})$ were observed which were attributed to freshly produced particles.

For CARRIBA $A_{D R Y}$, we can divide the campaign into three major periods in terms of aerosol load. The first half of CARRIBA $_{\text {DRY }}$ was influenced by Saharan dust layers in a height up to $3 \mathrm{~km}$ height indicated by an increased volume depolarization ratio. This period was interrupted by a comparable clean period ( 8 to 12 April) which coincides with higher cloudiness but no precipitation. Partly the dust was mixed down leading to increased number concentration at ground. The dust disappeared completely on 17 April when the wind in the SCL turned to a more northeasterly direction advecting clean marine air masses. About $50 \%$ of the aerosol particle concentration at ground was caused by Aitken-mode particles $<80 \mathrm{~nm}$ in the SCL for all the flights performed from 18 to 20 April. In the CL the weak wind from the south-west was advecting air masses from the Caribbean area (Fig. 6). Thus, this CL was influenced by extensive biomass burning activity observed in the entire Caribbean area and also on Barbados (see MODIS fire maps for the period from 17 to 21 April, not shown here) resulting in particle number concentrations up to $800 \mathrm{~cm}^{-3}$ - the highest mean values observed during the two campaigns. Therefore, although the mean particle number concentrations in the SCL and CL are comparable, the reason for the high numbers is completely different. A period with low aerosol burden and the lowest observed CCN concentration of $\sim 60 \mathrm{~cm}^{-3}$ was observed from 22 to 24 April. The supersaturation in the miniCCNc was fixed at $0.25 \%$ during all profiling. Again, on 24 April 2011 there was a very high concentration of Aitken mode particles with a peak around 30 to $40 \mathrm{~nm}$ which results in increased total number but low $\mathrm{CCN}$ concentrations.

The clouds usually respond to a changing aerosol number concentration in the SCL in a well-known way, where with decreasing aerosol particle number concentration the droplets will become bigger. As a measure for the mean size of the cloud droplets, Fig. 6e shows the effective radius de- rived from the droplet size distributions together with the retrieved values from the radiation measurements. A detailed analysis of the droplet size distributions of different cloud types under different aerosol conditions will be published elsewhere. The range of in-situ observed $r_{\text {eff }}$ is from 7 to $18 \mu \mathrm{m}$. The highest values of $r_{\mathrm{eff}}$ have been observed at the end of CARRIBA $A_{D R Y}$, identified as a period with the lowest aerosol number concentrations for particles $>80 \mathrm{~nm}$ in the cloud layer. The smallest cloud droplets in terms of $r_{\text {eff }}$ have been measured in the period where the trades were disturbed and the aerosol laden air masses from the Caribbean region where prevailing over Barbados.

In general, during phases when aerosol was advected from Africa during CARRIBA ${ }_{W E T}$, it was often a mixture of dust and biomass burning, both originating from the African continent. In contrast, for respective phases dur-

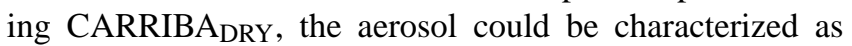
dust events with higher volume depolarization ratios. A further difference between the two campaigns was, that during CARRIBA $_{D R Y}$ we also took measurements within air masses originating from the Caribbean region with enhanced particle number concentrations due to biomass burning.

\section{The trades as a natural laboratory for aerosol-cloud- turbulence-radiation interaction studies}

In this part of the paper we discuss the trade wind region as a natural laboratory for aerosol-cloud-turbulence-radiation interaction, that is, the four leading topics of CARRIBA. We draw motivation from Malkus' insight (Malkus, 1954) that due to the absence of frontal systems the synoptic conditions are relatively stable, so that similar stratification, moisture, and turbulence are observed over relatively long periods of time. With negligible variability of the sea surface temperature over a one-month period or so, lifting condensation level is nearly constant so that cloud observations at the same height yield essentially the same adiabatic LWC.

The aim of this section is to illustrate how within such a relatively stable environment the fine-scale measurements during CARRIBA, that are unique due to the deployed measurement setup and therefore different from previous studies done in the trades, can be used to study aerosol-cloudturbulence-radiation interactions. The measurement strategy that includes collocated cloud and radiation properties, high resolution energy dissipation rate, and fast response aerosol and $\mathrm{CCN}$, provide a unique perspective on interactions between these factors. In the following, we contrast measurements on two days with typical marine (pristine) conditions, but that differ in their exact aerosol load and CCN number concentration. The aerosol and resulting CCN in the SCL are considered to be the setting parameters for the "cloud laboratory" and the resulting cloud microphysical properties are investigated, and the consequences for selected cloudturbulence processes and radiation effects are discussed. All 


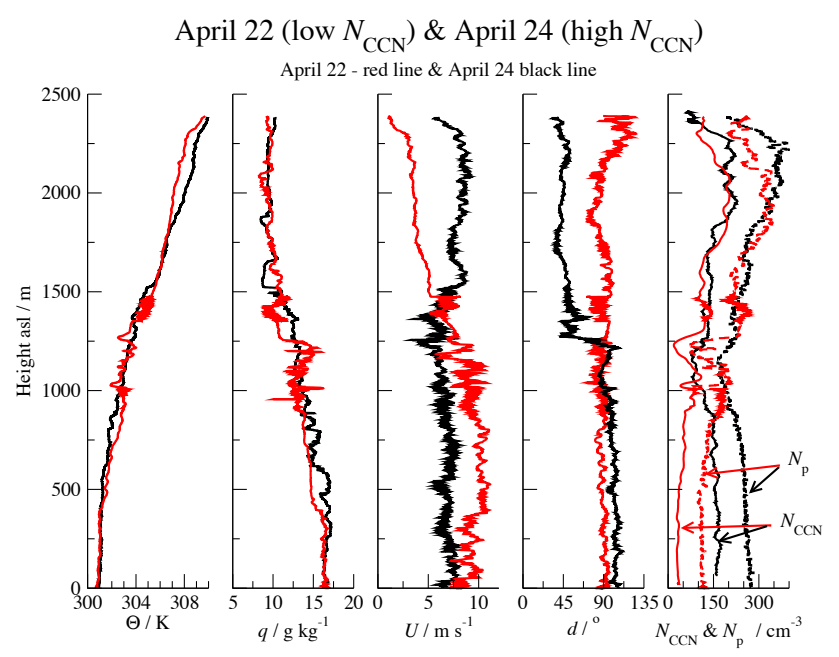

Fig. 7. Profiles of 20 April (black line) and 22 April (red line) derived from the first ascent of each flight. Shown are the potential temperature $\Theta$, the water vapor mixing ratio $q$, horizontal wind velocity $U$ and direction $d$ and $\mathrm{CCN}$ number concentration $N_{\mathrm{CCN}}$ at $0.25 \%$ supersaturation, and aerosol particle number concentration $N_{\mathrm{p}}$.

measured mean SCL and in-cloud parameters are summarized in Table 2 for both days.

\subsection{Vertical profiles of meteorology and aerosol}

Figure 7 shows vertical profiles of temperature, humidity, wind and number concentrations of aerosol and CCN sampled on 22 April (red lines) and 24 April (black lines). All $\mathrm{CCN}$ are measured at $0.25 \%$ supersaturation. These profiles were measured in clear-sky regions. The two days are similar in terms of their stratification of the SCL, which is almost identical for heights below $300 \mathrm{~m}$, although the transition layer in the range between 400 and $600 \mathrm{~m}$ is slightly drier on 22 April. Whereas 22 April experienced fairly strong easterly winds throughout the lower boundary layer, 24 April experienced weaker easterly to southeasterly winds, with a more pronounced turning of the winds above $1 \mathrm{~km}$.

The total aerosol number concentration $N_{\mathrm{p}}$ is nearly constant with height between the surface and $850 \mathrm{~m}$ on both days. However, the absolute values differ significantly, with $110 \mathrm{~cm}^{-3}$ for 22 April and $270 \mathrm{~cm}^{-3}$ for 24 April. Above $\sim 1000 \mathrm{~m}$ both cases are almost identical with a slight increase of $N_{\mathrm{p}}$ and a local maximum around $2250 \mathrm{~m}$.

The measured CCN number concentration $N_{\mathrm{CCN}}$ in the SCL was $40 \mathrm{~cm}^{-3}$ for 22 April compared to $160 \mathrm{~cm}^{-3}$ for 24 April. For heights above $1000 \mathrm{~m}$ the $\mathrm{CCN}$ are nearly the same for both days and strongly correlated with $N_{\mathrm{p}}$. The measured $\mathrm{CCN}$ at $0.25 \%$ supersaturation are taken as a proxy for the adiabatic cloud droplet number concentrations although the real supersaturation at cloud level and, therefore, the activa-

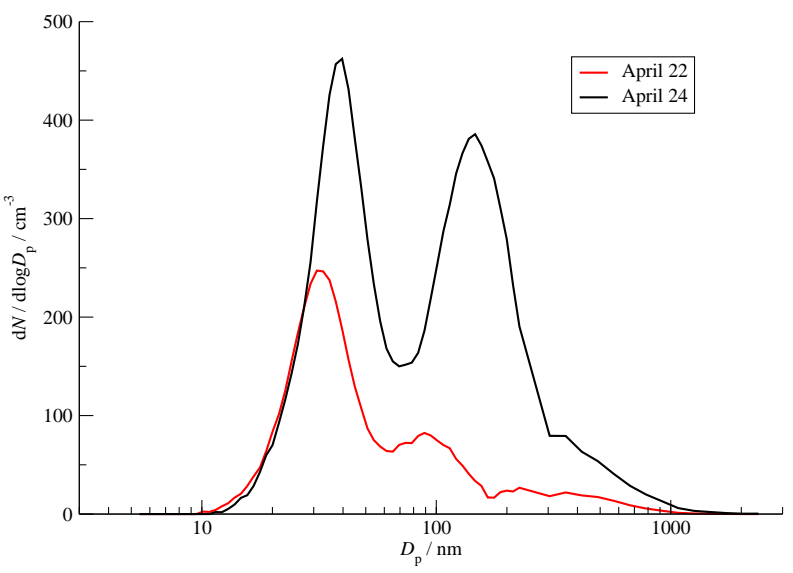

Fig. 8. Aerosol number size distributions measured in the SCL (below $400 \mathrm{~m}$ ) on 22 and 24 April.

tion diameter is a function of updraft velocity and aerosol properties at cloud base and will be different for both days.

\subsection{Aerosol and $\mathrm{CCN}$ properties: the setting parameter}

Because the different aerosol properties - in terms of number concentration and size distribution - are considered the main setting parameters for the cloud response, we take a closer look at the aerosol and CCN properties in the subcloud layer. Figure 8 shows the aerosol number size distributions measured in the SCL (here defined as a height below $400 \mathrm{~m}$ ) for both days. The differences are striking: both distributions show an Aitken mode with a peak at around 30 to $40 \mathrm{~nm}$, but with doubling of the number concentration on 24 April, the accumulation mode with a peak slightly above $100 \mathrm{~nm}$ is only pronounced on 24 April. We speculate that most likely the aerosol particles in this size range have been removed by wet deposition.

In order to understand the relationship between aerosol particle properties in the SCL and activation at cloud base height - where no direct ACTOS measurements are possible - a box model (Simmel and Wurzler, 2006) is applied. The model is initialized with the measured aerosol size distributions in the SCL and run for different fixed updraft velocities in the range of 0.5 to $4 \mathrm{~m} \mathrm{~s}^{-1}$, which are typical values for shallow trade wind clouds. A particle hygroscopicity of $\kappa=0.7$ (Petters and Kreidenweis, 2007) was assumed, which is the mean value estimated for the CARRIBA campaign. Figure 9 shows the results in terms of activated particles (solid lines) and corresponding activation diameter (dotted lines). For 22 April, measured $N_{\mathrm{CCN}}$ corresponds well to the modeled number concentrations of activated particles at low updrafts of up to $1 \mathrm{~m} \mathrm{~s}^{-1}$. On 24 April, the model results and measurements agree only for the weakest updraft considered in our calculations. The uncertainty bars reflect the variability of the measured aerosol properties. The modeled activation diameter is in general higher for 24 April compared to 


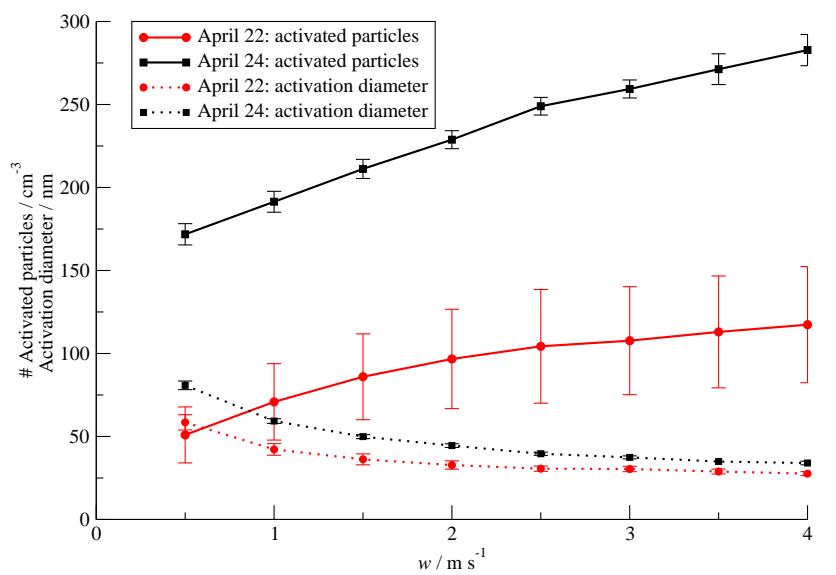

Fig. 9. Model results of activated aerosol particles and activation diameter as a function of updraft velocity $w$. The box model was initiated with observed aerosol conditions in the SCL on 22 and 24 April.

22 April, assuming the same updraft velocity, which is due to different supersaturation at cloud base caused by different $N_{\mathrm{CCN}}$. This means that low aerosol concentrations could lead to higher supersaturation at cloud base, that is, the cloud system partly balances low aerosol concentration by shifting the activation diameter to smaller values, thereby increasing the droplet number concentration.

\subsection{The cloud response}

On both days about 10 individual cumulus clouds were sampled close to cloud top (Fig. 10a). The measurement height was between 1400 to $1750 \mathrm{~m}$ on 22 April and around $1700 \mathrm{~m}$ on 24 April. The typical flight path during cloud penetration was a few hundred meters. The dynamics of the two cloud regions is qualitatively comparable with typical updrafts of 2 to $4 \mathrm{~m} \mathrm{~s}^{-1}$ but with updrafts of up to $8 \mathrm{~m} \mathrm{~s}^{-1}$ in single cloud cores (Fig. 10b). Downdrafts of about $-2 \mathrm{~m} \mathrm{~s}^{-1}$ were often observed at cloud edges, whereas between the clouds the vertical velocity is around zero. The minimum relative humidity between the clouds (not shown here) was about 85 to $90 \%$ for both days. The LWC measured with the PVM-100A is slightly higher on 24 April compared to 22 April (Fig. 10c) which is obviously caused by the different measurement heights. A height difference of $300 \mathrm{~m}$ results in a change of the adiabatic LWC of roughly $0.3 \mathrm{~g} \mathrm{~m}^{-3}$ which agrees with the observed differences in the peak LWC. Figure 10d shows the droplet sizes measured with the PDI. The cloud periods marked with the two boxes are selected for further analysis and comprise 16000 droplet counts each. It is quite obvious that different maximum droplet sizes were sampled during the two days. This can also be seen by the droplet size distribution shown in Fig. 11. The droplet size distribution of April 22 yields a mean volume diameter $d_{\mathrm{MVD}}=38 \mu \mathrm{m}$ compared to $27 \mu \mathrm{m}$ for 24 April.

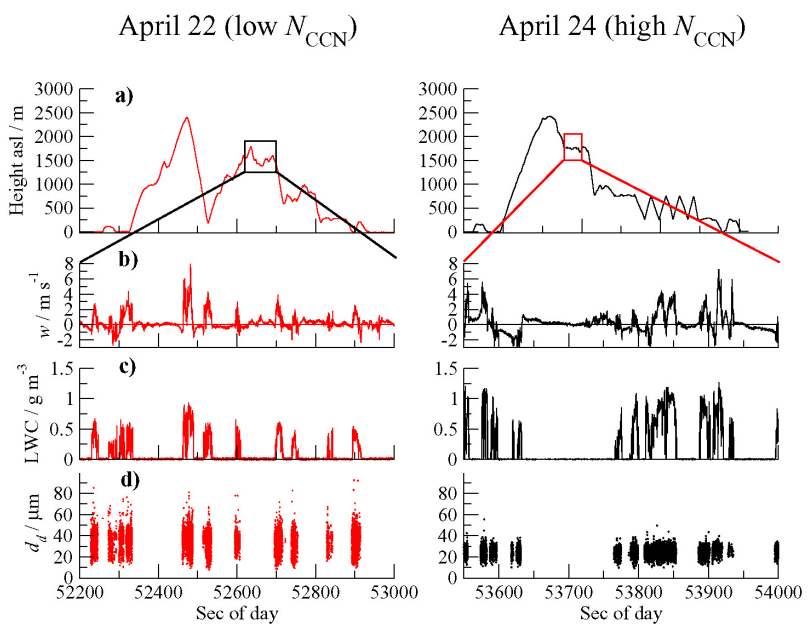

Fig. 10. Cloud observations performed on 22 April (low $N_{\mathrm{CCN}}$ ) and 24 April (high $N_{\mathrm{CCN}}$ ). The upper panel shows the measurement height of ACTOS in $m$ above sea level with the boxes indicating the considered cloud regions. The following panels show the vertical velocity $w$, liquid water content LWC as observed by the PVM, and the lowest panel shows the droplet sizes $d_{\mathrm{d}}$ as measured with the PDI for the analyzed cloud part. All $x$ axes are in seconds of the day.

During the two flight dates the PDI was slightly misaligned and this had two consequences. First, as described by Chuang et al. (2008), the PDI sample volume is determined by analyzing the distribution of droplet transit times. The low signal-noise ratio (SNR) resulting from misalignment led to unreliable transit times, so that a reliable estimate of the sample volume could not be obtained. Second, the low SNR also resulted in a droplet diameter threshold that is higher than usual. It should be emphasized, however, that because the PDI droplet diameter measurement is based on phase differences in Doppler shifts, the droplet size measurements are still accurate. Because of the relatively clean conditions with a typically broad size distribution, the measured size histograms can be taken as reliable for $d_{d}$ greater than approximately $10 \mu \mathrm{m}$. The lack of a sample volume correction implies that the size distribution resulting from the distribution of raw counts shown in Fig. 11 would have a slightly suppressed large-drop tail. However, that effect is minor and does not alter the qualitative conclusions reached from the comparison of the two size distribution shapes. Droplet number densities were obtained through an alternate measurement using a hot wire. The use of a hot-wire anemometer in clouds was discussed in Siebert et al. (2007) and successfully applied in Siebert et al. (2010b). Here, we modified the method and used the detected spikes from impacting cloud droplets to determine the droplet number density. The same type of hot wire and the same equations to estimate the swept volume were used as described in Siebert et al. (2007). An independent evaluation of this method using data from a 

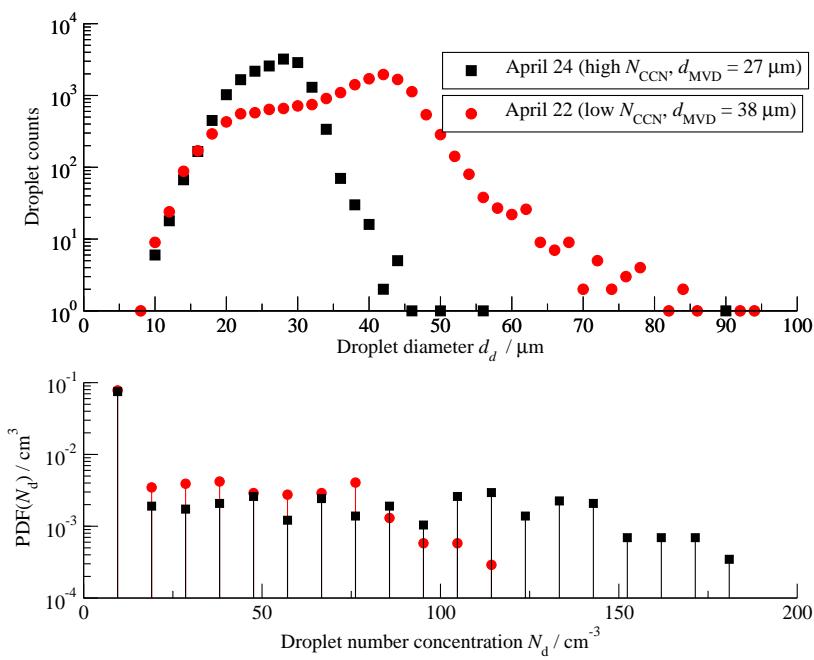

Fig. 11. Droplet size distributions (upper panel) for the cloud regions marked in Fig. 10. For both distributions 16000 droplets are considered. The lower panel shows the probability density function (PDF) of droplet number concentrations derived from hot-wire measurements.

flight with a properly aligned PDI showed agreement within $\sim 20 \%$.

The results are plotted in terms of PDFs of local concentrations averaged over one-second periods in the lower panel of Fig. 11. The arithmetic mean for 22 and 24 April was $42 \pm 26 \mathrm{~cm}^{-3}$ and $80 \pm 46 \mathrm{~cm}^{-3}$, respectively. It has to be pointed out that these estimates are based on only a few cloud penetrations and the variability from cloud to cloud is quite high which explains the high standard deviation of the estimated droplet concentrations.

The LWC is proportional to $d_{\mathrm{MVD}}^{3} \cdot N_{d}$, so we therefore expect cloud droplet diameter and number density to relate as

$$
\left(d_{\mathrm{MVD}}^{(22)} / d_{\mathrm{MVD}}^{(24)}\right)^{3} \approx\left(N_{d}^{(24)} / N_{d}^{(22)}\right),
$$

where superscripts in brackets are used at variables to distinguish between the two different days. This is fulfilled with $N_{d}^{(22)}=42 \mathrm{~cm}^{-3}$ and $N_{d}^{(24)}=80 \mathrm{~cm}^{-3}$ in the limit of uncertainties. Assuming that $N_{\mathrm{CCN}}$ at cloud base equals $N_{d}$ under adiabatic conditions and that the estimate of $N_{\mathrm{CCN}}$ might be statistically more reliable, we find with measured $N_{\mathrm{CCN}}^{(22)}=40 \mathrm{~cm}^{-3}$ and $N_{\mathrm{CCN}}^{(24)}=110 \mathrm{~cm}^{-3}$ the relation above nearly exactly fulfilled. This result supports the assumption that the main difference between the two cases is the size distribution (e.g., $\left.d_{\mathrm{MVD}}\right)$ and the droplet number concentration, all else being quite similar.

However, the most obvious difference in terms of droplets is the much broader droplet size distribution on 22 April with maximum droplet sizes of up to $95 \mu \mathrm{m}$. It is very likely that the largest drops have grown by collision coalescence, and these days therefore serve as contrasting examples for the
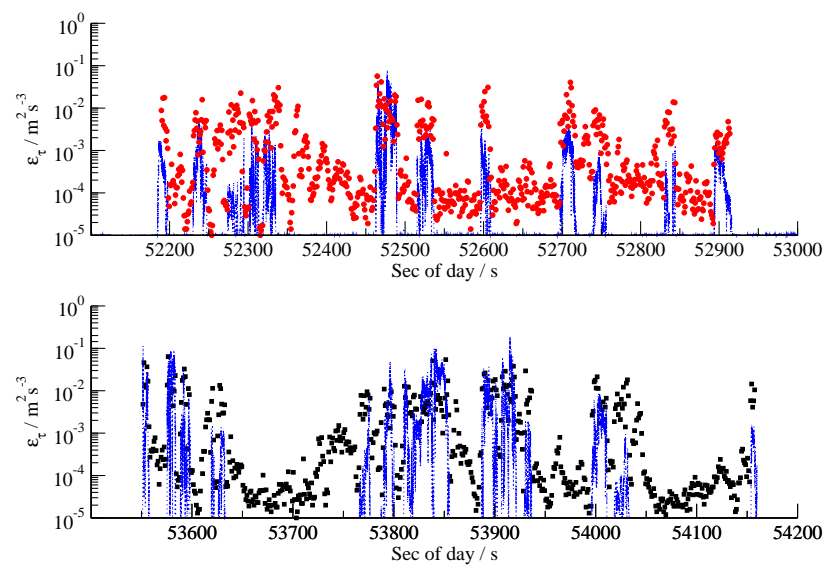

Fig. 12. Time series of local energy dissipation rates $\varepsilon_{\tau}$ (symbols) with each point representing a one-second average. The dotted blue lines indicate cloud events (unscaled LWC).

onset of the warm rain process. This is discussed further, after describing the cloud turbulence measurements.

\subsection{In-cloud turbulence}

Mixing and entrainment in clouds depend on the cloud turbulence. In order to determine if the turbulence conditions are similar for both days, the local energy dissipation rate $\varepsilon_{\tau}$ as a measure for local turbulence is estimated. Here, $\varepsilon_{\tau}$ is estimated from second-order structure functions for nonoverlapping sub-records of length $\tau=1 \mathrm{~s}$ (see Siebert et al. (2006b) for a detailed discussion of the method). The time series of $\varepsilon_{\tau}$ is shown in the upper panel of Fig. 12 with a logarithmic $y$ axis (same range in both plots).

The energy dissipation rate jumps significantly between outside and inside clouds, as expected. Although within clouds there is substantial variability in the energy dissipation rate, no clear relationship exists between $\varepsilon_{\tau}$ and LWC. The tendency for high $\varepsilon_{\tau}$ to occur near cloud edges, where mixing is occurring, relative to cloud cores, is offset by a slight trend for increasing $\varepsilon_{\tau}$ with LWC. On both days the qualitative behavior is the same, with mean values of $\varepsilon_{\tau}$ of $2 \times 10^{-3}$ and $3 \times 10^{-3} \mathrm{~m}^{2} \mathrm{~s}^{-3}$. This difference is smaller than the uncertainties related to estimating $\varepsilon_{\tau}$ and therefore not considered significant. The mean standard deviations of the vertical velocities (cf. Fig. 10b) are also similar at 0.5 and $0.6 \mathrm{~m} \mathrm{~s}^{-1}$.

\subsection{Effects of differences in cloud microphysics on turbulent mixing and droplet-droplet interaction}

From the results of the previous subsections we can safely conclude that the macroscopic cloud characteristics, including not only thermodynamic properties and stratification, but also the turbulent flow field, are comparable for both cases with the main differences in cloud microphysics being due 
to the different aerosol loads on these days. Thus we may explore the question, "Can aerosol influence the behavior of small-scale mixing?", as posed by Feingold and Siebert (2009). When discussing cloud mixing, for example mixing of sub-saturated air from the environment with saturated cloud parcels, two extremes are often considered: (i) turbulent mixing is finished before the droplets can react to the new thermodynamic conditions (homogeneous mixing) or (ii) turbulent mixing is comparably slow and the droplets react more or less instantaneously to the new conditions (inhomogeneous mixing).

The degree to which mixing tends to one of these extremes can be expressed through the Damköhler number $D a=\tau_{\mathrm{m}} / \tau_{\mathrm{p}}$, where $\tau_{\mathrm{m}}=\left(l^{2} / \varepsilon\right)^{1 / 3}$ is the turbulent mixing timescale for length scale $l$, and $\tau_{\mathrm{p}}$ is a microphysical response time (Lehmann et al., 2009). The latter is usually given by the phase relaxation time $\tau_{\mathrm{p}} \approx\left(4 \pi N_{d} d_{d} D_{v}\right)^{-1}$, where $D_{v} \approx 2.2 \times 10^{-5} \mathrm{~m}^{2} \mathrm{~s}^{-1}$ is the coefficient of water vapor diffusion (see Korolev and Mazin (2003); Kostinski (2009) for example). For $D a<1$ the mixing approaches the more homogeneous scenario and for $D a>1$ the mixing will be more inhomogeneous. Lehmann et al. (2009) expressed the transition from inhomogeneous mixing at large scales to homogeneous mixing at small scales in terms of a transition length scale $l_{\star}=\varepsilon^{1 / 2} \tau_{\mathrm{p}}^{3 / 2}$, that is, defining a length scale at which $D a=1$ is valid. This concept overcomes the problem of defining an arbitrary turbulent mixing length scale $l$. Assuming $l_{\star}$ is within the inertial subrange, for $l<l_{\star}$ the mixing is expected to be homogeneous and for $l>l_{\star}$ it tends to be inhomogeneous.

The simultaneous and high-resolution measurements of energy dissipation rate and droplet size distribution allow the transition length to be estimated locally for the two cases. In Fig. 13 the PDFs of the transition length scales are presented for 22 and 24 April. Because the mean turbulence conditions are similar for both days $l_{\star}$ is mostly distinguished by the product of $N_{d}$ and $d_{d}$. Using mean values and taking $N_{d}$ derived from the hot-wire measurements we find $N_{d} d_{d}=1520 \mathrm{~cm}^{-3} \mu \mathrm{m}$ for April 22 versus $2240 \mathrm{~cm}^{-3} \mu \mathrm{m}$ on 24 April resulting in rather similar distributions of transition length scale. The transition length scale is typically on the order of a few meters or less, that is, under most conditions inhomogeneous mixing will be observed throughout the majority of the energy cascade. The energy cascade ends at scales typically on the order of $1 \mathrm{~cm}$ and below $(\approx 10$ times the Kolmogorov length scale), so for the observed distribution of transition length scales there is usually one to two decades over which homogeneous mixing should operate. Analysis of variations of the mean volume diameter with cloud dilution quantified through $N_{d}$ (e.g., Burnet and Brenguier, 2007) show $d_{\text {MVD }}$ quite uniform even with large decreases in droplet number density near cloud edge. This can be interpreted either as indicative of strongly inhomogeneous mixing or homogeneous mixing with "environmental" air that is very

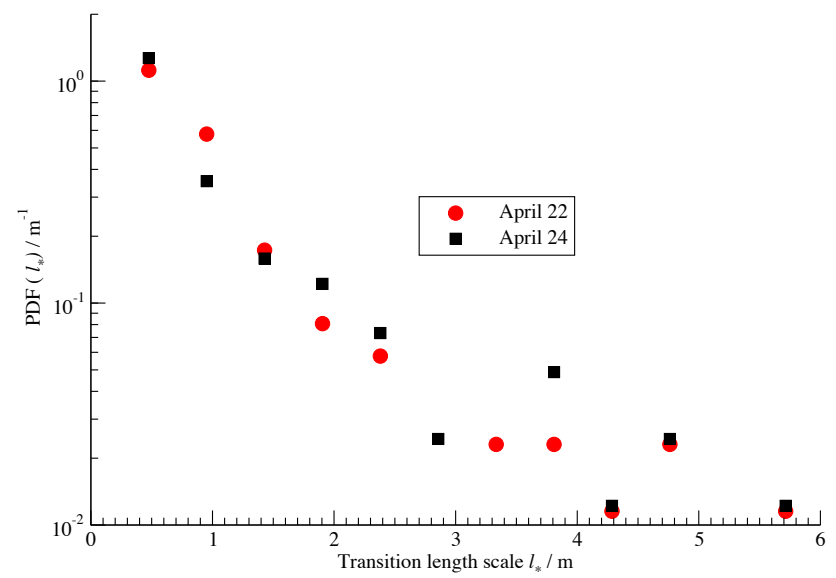

Fig. 13. Probability density function of the transition length scale $l_{\star}$ for 22 and 24 April.

similar in its thermodynamic properties to the cloud. The latter could be due to, for example, mixing with humid air in subsiding shells (e.g., Heus and Jonker, 2008).

No clear evidence is observed for an aerosol effect on the homogeneity of mixing when contrasting these two days. Nevertheless, although the two days are similar in terms of turbulent mixing it should be noted that the transition lengths scales are in general about one order of magnitude larger compared to values estimated for continental clouds on the order of a decimeter or so (Lehmann et al., 2009). In other words, the conditions encountered during CARRIBA are promising for further investigation of cloud mixing because there is a larger range of scales over which to observe homogeneous mixing compared to continental sites.

Another important aspect of cloud turbulence is its influence on cloud droplet motion and the resulting droplet collision rate. Besides general reviews (Shaw, 2003; Vaillancourt and Yau, 2000) this issue was recently discussed in Siebert et al. (2010a) based on observations in atmospheric clouds, laboratory, and model results. Under a few assumptions (Siebert et al., 2010a), the droplet motion can be approximated by $\mathrm{d} v / \mathrm{d} t=(u-v) / \tau_{d}+g$, where $v$ is the droplet velocity vector, $u$ is the flow velocity vector, $\tau_{d}$ is the inertial droplet response time and $g$ is the gravitational acceleration vector. That is, relative motion between a droplet and the surrounding fluid arises because of gravitational settling and droplet inertia. Relative motion between two droplets therefore can be generated by different inertial droplet response times which is mainly caused by different droplet sizes $\left(\tau_{d} \propto d_{d}^{2}\right)$ and differences of the turbulent velocity at the droplet location. Usually, the droplet inertia is expressed by the Stokes number $S t=\tau_{d} / \tau_{\eta}$ which describes the relation between inertial droplet response time and a typical turbulence response time (Kolmogorov timescale) $\tau_{\eta}=(v / \varepsilon)^{1 / 2}$. The other important relation is between local fluid particle acceleration and gravitation which is expressed by the 


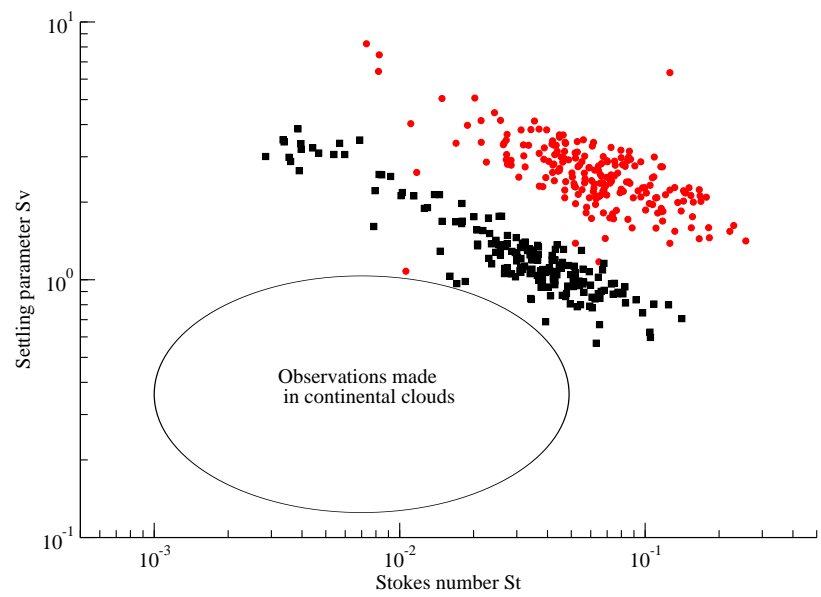

Fig. 14. Stokes and settling parameter space for 22 and 24 April. For comparison, the black ellipse marks the parameter space occupied by observations made in continental clouds (Siebert et al., 2010a).

Froude number $F r=\sigma_{\mathrm{a}} / g$. The standard deviation of fluid acceleration $\sigma_{\mathrm{a}}$ is a function of local turbulence. The relative importance of gravitational settling and droplet inertia is captured by the settling parameter $S v$, the ratio of the terminal settling velocity $v_{\mathrm{t}}$ and the turbulent velocity $v_{\eta}: S v=v_{\mathrm{t}} / v_{\eta}$. It can also be shown that the three dimensionless numbers are not independent from each other and two of them are enough to characterize the dimensionless parameter space (Wang and Maxey, 1993; Vaillancourt and Yau, 2000):

$S v=\frac{S t}{F r}$

We can represent the relative importance of gravity and inertia by considering a $S t-S v$ parameter space, as shown in Fig. 14, with each point representing an average sampled over $20 \mathrm{~m}$. The difference between the measurements performed on 22 and 24 April is quite obvious and the two parameter spaces are well separated from each other. Because Fr is solely a function of the turbulent velocity field, St and $\mathrm{Sv}$ are both $\propto d_{d}^{2}$, which explains the clear shift of the points in the upper right direction for the relatively lowaerosol day with larger droplets. In addition to the CARRIBA observations the black ellipse indicates roughly the parameter space covered by similar measurements performed with the same measurement system in continental clouds over Europe (Siebert et al., 2010a). Both CARRIBA observations are shifted by about one order of magnitude in both directions compared with the measurements in continental clouds which are characterized by mean $d_{d} \approx 10 \mu \mathrm{m}$ and $N_{d} \approx 300$ to $800 \mathrm{~cm}^{-3}$ (cf. Lehmann et al., 2009). From this analysis we conclude that droplet-droplet interaction and, therefore, the coalescence process and drizzle production is much more effective under the pristine conditions of the trades. Moreover, the differences observed between 22 and 24 April are quite obvious and the droplet size distribution for 22 April
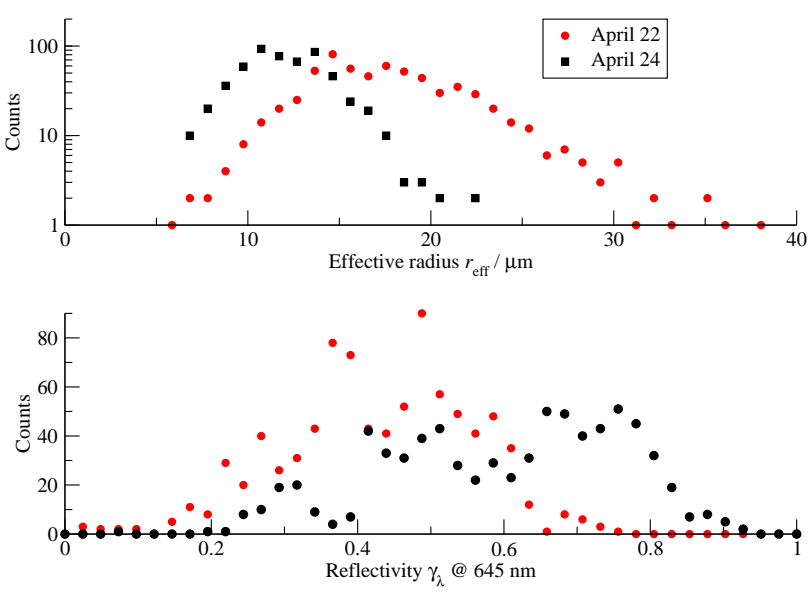

Fig. 15. Frequency distributions of the effective radius $r_{\text {eff }}$ (upper panel) and reflectivity (lower panel) at $645 \mathrm{~nm}$ measured with SMART-HELIOS.

(Fig. 11) indicates already the onset of drizzle production with $d_{d}>60 \mu \mathrm{m}$.

\subsection{Radiation effect}

The upper panel of Fig. 15 shows PDFs of the effective droplet radius $r_{\text {eff }}$ retrieved from radiation measurements collected by SMART-HELIOS above the clouds. The retrieval approach and applied data filter, which minimizes the influence of 3-D radiative effects, are discussed by Werner et al. (2013a, b). Peak values of $r_{\text {eff }}$ are shifted from about $12 \mu \mathrm{m}$ on 24 April to about $18 \mu \mathrm{m}$ on 22 April. Moreover, the PDF for 22 April is significantly broader with observed $r_{\text {eff }}=5$ to $38 \mu \mathrm{m}$ compared to 24 April ( $r_{\text {eff }}=5$ to $24 \mu \mathrm{m}$ ). The decrease in droplet sizes on 24 April leads to an increase in observed spectral cloud top reflectivity $\gamma_{\lambda}$ (here at a wavelength $\lambda=645 \mathrm{~nm}$ in the visible wavelength range), depicted in the lower panel of Fig 15. Observed $\gamma_{\lambda}$ go up to 0.9 on 24 April, while on 22 April maximum values for $\gamma_{\lambda}$ are in the range of 0.65 . These measurements thus allow for an evaluation of the well-known, but challenging to observe, Twomey effect (Twomey, 1977).

\section{Summary and discussion}

This article provides a general introduction to the two CARRIBA campaigns performed in the climatic wet season (November 2010) and dry season (April 2011) on and nearby Barbados. With the helicopter-borne ACTOS and SMARTHELIOS payloads 31 research flights have been conducted, which were supported by additional ground-based aerosol observations and remote-sensing at the east coast of Barbados. The goal was to explore the fine-scale structure of trade wind cumuli with a focus on cloud microphysics, aerosol, radiation, and turbulent processes and their various interactions 
and feedbacks. As one unique feature of this campaign, all airborne and ground-based measurements have been realized in a comparable small square area of roughly $100 \mathrm{~km}^{2}$ off the coast which allows an optimal inter-comparison of the different observations.

Even though most flights were performed under quite similar conditions in terms of the macroscopic cloud structure - fluffy shallow trade wind cumuli often combined with a few thin stratiform layers were prevailing - the microscopic structure below and in cloud, in terms of aerosol and mean cloud droplet size, was highly variable. On different flights the observed effective radii span a range between 7 and $18 \mu \mathrm{m}$. The two campaigns had slightly different characteristics in terms of aerosol loading and origin. During both campaigns, phases with low and high particle number concentrations occurred, with values as low as $100 \mathrm{~cm}^{3}$ (typical clean marine conditions) and higher than $500 \mathrm{~cm}^{3}$ (typical polluted conditions). Increased particle number concentrations in the $\mathrm{CCN}$ size range were observed often when air masses originated from Africa. During CARRIBAWET, these aerosols were a mixture of dust and aerosol from biomass burning, while during CARRIBA $A_{D R Y}$ the aerosols originating from Africa were mainly dust. Additionally, during CARRIBA ${ }_{D R Y}$ measurements were made in clouds influenced by biomass burning aerosol from the Caribbean. Altogether, a wide range of different situations in terms of aerosol loading was observed during the two campaigns which allows to systematically investigate the influence of aerosol on the cloud microstructure.

In order to illustrate the effect of different aerosol loads on cloud structure including turbulent mixing and radiation effects, two days were selected with essentially all thermodynamic and dynamical aspects including updrafts and smallscale turbulence were equal, but with different aerosol concentration in the SCL. The day with higher aerosol loading shows proportionally higher $\mathrm{CCN}$ concentration at equal supersaturation. The actual peak supersaturations at cloud base are expected to be somewhat different, thereby decreasing the magnitude of the change in droplet number concentration. The clouds responded such that on the day with lower aerosol loading larger droplets were observed.

In spite of differences in microphysical properties, turbulent mixing is essentially unchanged, exhibiting a very similar range of transition length scales (mostly lying between 0.1 to $1 \mathrm{~m}$ ), and showing strong fluctuations in local droplet number concentration, with relatively small changes in mean volume diameter of droplets, that is, inhomogeneous mixing or homogeneous mixing with air possessing very similar thermodynamic properties as the cloud (e.g., humid environment or subsiding shells). The concept that there is a strong aerosol effect on mixing is not clearly observed.

The difference in microphysical properties does lead to a significant shift in the dimensionless parameter space that accounts for the relative roles of gravitational settling and turbulence in initiation of collision coalescence (Wang and
Maxey, 1993; Woittiez et al., 2009). Droplets shift to higher Stokes numbers, with significant numbers of droplets having $S t>0.1$, even with $S v \sim 1$, which has been shown to be a range in which clustering and relative velocity enhancements to the collision rate become significant (Wang and Maxey, 1993; Saw et al., 2008). In the cloud regions with lower energy dissipation rate, and therefore lower St, the settling parameter approaches $S v \sim 8$ and therefore the part of parameter space in which gravitational settling begins to be the dominant mechanism for collision rate. The emergence of drizzle in some, but not all of the clouds sampled on the low-aerosol day, is strongly suggestive of a coalescence process that is just at the threshold of being effective.

The different microphysical properties also lead to an unambiguous shift in the optical properties of the clouds. The date with higher aerosol concentration and therefore smaller mean droplet radius shows a significant shift in the range of observed reflectivities at $645 \mathrm{~nm}$, from approximately 0.3 to 0.6 on the low-aerosol day, to approximately $0.4-0.8$ on the high-aerosol day. The uniformity of other thermodynamic and dynamic properties, together with the closely collocated microphysical and radiation measurements, provide strong support for the higher reflectivities being directly attributed to the Twomey effect.

The two CARRIBA campaigns, together with data available from the MPI-M BCO, provides us with a large data set which will be explored in more detail. This article outlined the conditions we encountered during the measurements in general, and gave an example of two cloud scenarios with different aerosol and cloud microphysical conditions but everything else being equal. These two cases could serve as an initial state for model studies on cloud-turbulence interaction.

Acknowledgements. We thank the experienced and highly engaged pilots Alwin Vollmer and Milos Kapetanovic for the terrific and safe helicopter flights in the Caribbean. Thanks also to Paul Archer from Horizon Helicopters and to National Helicopters in Canada for organizing and providing the helicopter service. Many thanks also to the team from the Barbados Concorde Experience who hosted the ACTOS and helicopter team. We thank Joe Prospero for access to his infrastructure at Ragged Point. Lutz Hirsch and Friedhelm Jansen are acknowledged for their help and experience during the preparation phase of the campaigns. We are grateful to Christoph Klaus and Dieter Schell from the enviscope company for their excellent technical support during the campaigns and acknowledge Damien Prescod from CIMH for his support in terms of local logistics. We thank Albert Ansmann for help with the interpretation of lidar data, Martin Simmel for providing his model, and gratefully acknowledge Deutsche Forschungsgemeinschaft (DFG) for funding this project (SI 1534/3-1 and WE 1900/18-1). Finally, we thank Patrick Chuang and the anonymous reviewer whose comments helped to significantly improve the manuscript.

The service charges for this open access publication have been covered by the Max Planck Society. 
Edited by: M. Krämer

\section{References}

Albrecht, B. A., Bretherton, C. S., Johnson, D., Scubert, W. H., and Frisch, A. S.: The Atlantic Stratocumulus Transition Experiment - ASTEX, B. Am. Meteor. Soc., 76, 889-904, 1995.

Augstein, E., Riehl, H., Ostapoff, F., and Wagner, V.: Mass and energy transports in an undisturbed atlantic trade-wind flow, Mon. Weather Rev., 101, 101-111, 1973.

Blyth, A. M., Lasher-Trapp, S., Cooper, W. A., Knight, C. A., and Latham, J.: The role of giant and ultragiant nuclei in the formation of early radar echoes in warm cumulus clouds, J. Atmos. Sci., 60, 2557-2572, 2003.

Burnet, F. and Brenguier, J.-L.: Observational study of the entrainment-mixing process in warm convective clouds, J. Atmos. Sci., 64, 1995-2011, 2007.

Chiu, J. C., Marshak, A., Knyazikhin, Y., Pilewski, P., and Wiscombe, W. J.: Physical interpretation of the spectral radiative signature in the transition zone between cloud-free and cloudy regions, Atmos. Chem. Phys., 9, 1419-1430, doi:10.5194/acp-91419-2009, 2009.

Chuang, P. Y., Saw, E. W., Small, J. D., Shaw, R. A., Sipperley, C. M., Payne, G. A., and Bachalo, W.: Airborne Phase Doppler Interferometry for Cloud Microphysical Measurements, Aerosol Sci. Technol., 42, 685-703, 2008.

Davidson, B.: The Barbados Oceanographic and Meteorological Experiment, B. Am. Meteor. Soc., 49, 928-934, 1968.

Feingold, G. and Siebert, H.: Cloud-Aerosol Interactions from the Micro to the Cloud Scale, in: Perturbed Clouds in the Climate System - Their Relationship to Energy Balance, Atmospheric Dynamics, and Precipitation, edited by: Heintzenberg, J. and Charlson, R. J., ISBN-10:0-262-01287-1, MIT Press, 2009.

Gerber, H., Arends, B. G., and Ackerman, A. S.: New microphysics sensor for aircraft use., Atmos. Res., 31, 235-252, 1994.

Hanuš, J., Malenovský, Z., Homolová, L., Kaplan, V., Lukeš, P., and Cudlín, P.: Potentials of the VNIR airborne hyperspectral system AISA Eagle, in: Symposium GIS Ostrava, (CZ), 27-30 January, 2008, 2008

Haywood, J. M., Pelon, J., Formenti, P., Bharmal, N., Brooks, M., Capes, G., Chazette, P., Chou, C., Christopher, S., Coe, H., Cuesta, J., Derimian, Y., Desboeufs, K., Greed, G., Harrison, M., Heese, B., Highwood, E. J., Johnson, B., Mallet, M., Marticorena, B., Marsham, J., Milton, S., Myhre, G., Osborne, S. R., Parker, D. J., Rajot, J.-L., Schulz, M., Slingo, A., Tanré, D., Tulet, P.: Overview of the Dust and Biomass-burning Experiment and African Monsoon Multidisciplinary Analysis Special Observing Period-0, J. Geophys. Res., 113, D00C17, doi:10.1029/2008JD010077, 2008.

Henrich, F., Siebert, H., Jäkel, E., Shaw, R. A., and Wendisch, M.: Collocated Measurements of Boundary-Layer Cloud Microphysical and Radiative Properties - A Feasibility Study, J. Geophys. Res., 115, D24214, doi:10.1029/2010JD013930, 2010.

Heus, T. and Jonker, H. J. J.: Subsiding shells around shallow cumulus clouds, J. Atmos. Sci., 65, 1003-1018, 2008.

Heymsfield, A. J. and McFarquhar, G. M.: Microphysics of INDOEX clean and polluted trade cumulus clouds, J. Geophys. Res., 106, 28653-82673, 2001.
Holland, J. Z. and Rasmusson, E. M.: Measurements of the atmospheric mass, energy, and momentum budget over a 500kilometer square of tropical ocean, Mon. Weather Rev., 101, 4455, 1973.

Kaufman, Y. J., Koren, I., Remer, L. A., Rosenfeld, D., and Rudich, Y.: The effect of smoke, dust, and pollution aerosol on shallow cloud development over the Atlantic Ocean, P. Natl. Acad. Sci., 102, 11207-11212, 2005.

Korolev, A. V. and Mazin, I. P.: Supersaturation of Water Vapor in Clouds, J. Atmos. Sci., 60, 2957-2974, 2003.

Kostinski, A. B.: Simple approximations for condensational growth, Environ. Res. Lett., 4, 015005, doi:10.1088/17489326/4/1/015005, 2009.

Langmuir, I.: The production of rain by a chain reaction in cumulus clouds at temperature above freezing, J. Meteorol., 5, 175-192, 1948.

Lehmann, K., Siebert, H., and Shaw, R. A.: Homogeneous and inhomogeneous mixing in cumulus clouds: Dependence on local turbulence structure, J. Atmos. Sci., 66, 3641-3659, 2009.

Malkus, J. S.: Some results of a trade-cumulus cloud investigation, J. Meteorol., 11, 220-237, 1954.

Malkus, J. S.: On the maintenance of the trade winds, Tellus, 8 , 335-350, 1956.

Malkus, J. S.: On the structure of the trade wind moist layer, Pap. Phys. Oceanogr. Meteorol., 12, 1-47, 1958.

Marshak, A., Wen Jr., G., J. A. C., Remer, L. A., Loeb, N. G., and Cahalan, R. F.: A simple model for the cloud adjacency effect and the apparent bluing of aerosols near clouds, J. Geophys. Res., 113, D14S17, doi:10.1029/2007JD009196, 2008.

Nuijens, L., Serikow, I., Hirsch, L., Lonitz, K., and Stevens, B.: The distribution and variability of low-level cloud in the NorthAtlantic trades, Q. J. Roy. Meteorol. Soc., submitted, 2013.

Petters, M. D. and Kreidenweis, S. M.: A single parameter representation of hygroscopic growth and cloud condensation nucleus activity, Atmos. Chem. Phys., 7, 1961-1971, doi:10.5194/acp-71961-2007, 2007.

Prospero, J. M. and Carlson, T. N.: Vertical and Areal Distribution of Saharan Dust over the Western Equatorial North Atlantic Ocean, J. Geophys. Res., 77, 5255-5265, 1972.

Prospero, J. M. and Lamb, P. J.: African droughts and dust transport to the Caribbean: Climate change implications, Science, 302, 1024-1027, 2003.

Rauber, R. M., Ochs III, H. T., Di Girolamo, L., Göke, S., Snodgrass, E., Stevens, B., Knight, C., Jensen, J. B., Lenschow, D. H., Rilling, R. A., Rogers, D. C., Stith, J. L., Albrecht, B. A., Zuidema, P., Blyth, A. M., Fairall, C. W., Brewer, W. A., Tucker, S., Lasher-Trapp, S. G., Mayol-Bracero, O. L., Vali, G., Geerts, B., Anderson, J. R., Baker, B. A., Lawson, R. P., Bandy, A. R., Thornton, D. C., Burnet, E., Brenguier, J-L., Gomes, L., Brown, P. R. A., Chuang, P., Cotton, W. R., Gerber, H., Heikes, B. G., Hudson, J. G., Kollias, P., Krueger, S. K., Nuijens, L., O’Sullivan, D. W., Siebesma, A. P., and Twohy, C. H.: Rain in shallow cumulus over the ocean, B. Am. Meteorol. Soc., 88, 1912-1928, 2007.

Reid, J. S., Westphal, D. L., Livingston, J. M., Savoie, D. L., Maring, H. B., Jonsson, H. H., Eleuterio, D. P., Kinney, J. E., and Reid, E. A.: Dust vertical distribution in the Caribbean during the Puerto Rico Dust Experiment, Geophys. Res. Lett., 29, 1151, doi:10.1029/2001GL014092, 2002. 
Roberts, G. C. and Nenes, A.: A continuous-flow streamwise thermal-gradient $\mathrm{CCN}$ chamber for atmospheric measurements, Aerosol Sci. Technol., 39, 206-221, 2005.

Roberts, G. and Nenes, A.: Miniaturizing the continous-flow streamwise thermal-gradient CCN chamber, in: Prodceedings of the 7th International Aerosol Conference, vol. 1, pp. 448-449, St. Paul, USA, 2006.

Rudich, Y., Khersonsky, O., and Rosenfeld, D.: Treating clouds with a grain of salt, Geophys. Res. Lett., 29, 2060, doi:10.1029/2002GL016055, 2002.

Saw, E. W., Shaw, R. A., Ayyalasomayajula, S., Chuang, P. Y., and Gylfason, A.: Inertial Clustering of Particles in High-ReynoldsNumber Turbulence, Phys. Rev. Lett., 100, 214501, 2008.

Schäfer, M., Bierwirth, E., Ehrlich, A., Heyner, F., and Wendisch, M.: Application of ground-based hyperspectral imaging to retrieve ice crystal shape and fields of cirrus optical thickness, Atmos. Meas. Tech. Discuss., 6, 1201-1238, doi:10.5194/amtd-61201-2013, 2013.

Schmidt, K. S., Feingold, G., Pilewskie, P., Jiang, H., Coddington, O., and Wendisch, M.: Irradiance in polluted cumulus fields: Measured and modeled cloud-aerosol effects, Geophys. Res. Lett., 36, L07804, doi:10.1029/2008GL036848, 2009.

Shaw, R. A.: Particle-turbulence interactions in atmospheric clouds, Annu. Rev. Fluid Mech., 35, 183-227, 2003.

Siebert, H., Franke, H., Lehmann, K., Maser, R., Saw, E. W., Schell, D., Shaw, R. A., and Wendisch, M.: Probing Fine-Scale Dynamics and Microphysics of Clouds with Helicopter-Borne Measurements, B. Am. Meteorol. Soc., 87, 1727-1738, 2006 a.

Siebert, H., Lehmann, K., and Wendisch, M.: Observations of small scale turbulence and energy dissipation rates in the cloudy boundary layer, J. Atmos. Sci., 63, 1451-1466, 2006 b.

Siebert, H., Lehmann, K., and Shaw, R.: On the use of a hot-wire anemometer for turbulence measurements in clouds, J. Atmos. Ocean. Tech., 24, 980-993, 2007.

Siebert, H., Gerashchenko, S., Lehmann, K., Gylfason, A., Collins, L. R., Shaw, R. A., and Warhaft, Z.: Towards understanding the role of turbulence on droplets in clouds: In situ and laboratory measurements, and numerical modeling, Atmos. Res., 97, 426437, 2010a.

Siebert, H., Shaw, R. A., and Warhaft, Z.: Statistics of small-scale velocity fluctuations and internal intermittency in marine stratocumulus clouds, J. Atmos. Sci., 67, 262-273, 2010b.

Simmel, M. and Wurzler, S.: Condensation and activation in sectional cloud microphysical models, Atmos. Res., 80, 218-236, doi:10.1016/j.atmosres.2005.08.002, 2006.

Smirnov, A., Holben, B. N., Savoie, D., Prospero, J. M., Kaufman, Y. J., Tanre, D., Eck, T. F., and Slutsker, I.: Relationship Between Column Aerosol Optical Thickness and In Situ Ground Based Dust Concentrations over Barbados, Geophys. Res. Lett., 27, 1643-1646, 2000.
Stevens, B.: On the growth of layers of non-precipitating cumulus convection, J. Atmos. Sci., 64, 2916-2931, 2007.

Stevens, B. and Feingold, G.: Untangling aerosol effects on clouds and precipitation in a buffered system, Nature, 461, 607-613, 2009.

Stommel, H.: Entrainment of air into a cumulus cloud, J. Meteorol., 4, 91-94, 1947.

Stommel, H.: Entrainment of air into a cumulus cloud II, J. Meteorol., 8, 127-129, 1951.

Tiedtke, M.: A Comprehensive Mass Flux Scheme for Cumulus Parameterization in Large-Scale Models, Mon. Weather Rev., 117, 1779-1800, 1989.

Twomey, S.: The influence of pollution on the shortwave albedo of clouds, J. Atmos. Sci., 34, 1149-1152, 1977.

Vaillancourt, P. A. and Yau, M. K.: Review of particle-turbulence interactions and consequences for cloud physics, B. Am. Meteorol. Soc., 81, 285-298, 2000.

Wang, L.-P. and Maxey, M. R.: Settling velocity and concentration distribution of heavy particles in homogeneous isotropic turbulence, J. Fluid Mech., 256, 27-68, 1993.

Wehner, B., Siebert, H., Ansmann, A., Ditas, F., Seifert, P., Stratmann, F., Wiedensohler, A., Apituley, A., Shaw, R. A., Manninen, H. E., and Kulmala, M.: Observations of turbulence-induced new particle formation in the residual layer, Atmos. Chem. Phys., 10, 4319-4330, doi:10.5194/acp-10-4319-2010, 2010.

Wehner, B., Siebert, H., Hermann, M., Ditas, F., and Wiedensohler, A.: Characterisation of a new Fast CPC and its application for atmospheric particle measurements, Atmos. Meas. Tech., 4, 823833, doi:10.5194/amt-4-823-2011, 2011.

Wendisch, M. and Brenguier, J.-L. (Eds.): Airborne Measurements for Environmental Research: Methods and Instruments., vol. ISBN: 978-3-527-40996-9, Wiley-VCH Verlag GmbH \& Co. KGaA, Weinheim, Germany, 2013.

Werner, F., Ditas, F., Siebert, H., Wehner, B., Pilewskie, P., and Wendisch, M.: Twomey Effect and Susceptibility of Maritime Trade Wind Cumuli, J. Geophys. Res., submitted, 2013a.

Werner, F., Siebert, H., Pilewskie, P., Schmeissner, T., Shaw, R. A., and Wendisch, M.: New airborne retrieval approach for trade wind cumulus properties under overlying cirrus, J. Geophys. Res., 118, 3634-3649, doi:10.1002/jgrd.50334, 2013 b.

Woittiez, E. J. P., Jonker, H. J. J., and Portela, L. M.: On the Combined Effects of Turbulence and Gravity on Droplet Collisions in Clouds: A Numerical Study, J. Atmos. Sci., 66, 1926-1943, 2009.

Woodcock, A. H., Kientzler, C. F., Arons, A. B., and Blanchard, D. C.: Giant condensation nuclei from bursting bubbles,, Nature, 172, 1144-1145, 1953 